\title{
La olvidada “Escuela Jesuítica” en la Italia prerromántica. De la conciencia criolla al nacionalismo emergente (La Provincia del Nuevo Reino de Granada)
}

The forgotten "Jesuit School " on preromantic Italy. Creole consciousness of the emerging nationalism (The Province of Nuevo Reino de Granada)

José del Rey Fajardo SJ ${ }^{*}$

\section{Resumen}

El presente artículo trata de diseñar un mapa conceptual de los aportes de "lo local” al nacionalismo emergente en la Provincia del Nuevo Reino de Granada. Se inicia con un inventario de la producción en el área de la geo-historia en donde emerge la figura del italiano Felipe Salvador Gilij con su Saggio di Storia Americana (Roma, 1780-1784). Escritor más conocido en la literatura científica europea de finales del siglo XVIII, quien además supo convocar los conocimientos de muchos de sus conmisioneros. Se completa su visión con los autores todavía inéditos como Antonio Salillas y Roque Lubián. En la historia de la cartografía se mencionan a Joaquín Subías y a Antonio Julián amén del propio Gilij. Otro ramo importante es el relativo a la Lingüística indígena tal como lo recoge el polígrafo Lorenzo Hervás y Panduro en su Catálogo de las lenguas de las naciones conocidas (Madrid, 1801). Un capítulo aparte merecería el estudio de la obra de los tres hermanos Julián, Antonio, Ignacio y Francisco Javier, por su excelente aporte a los haberes intelectuales de la Universidad Javeriana colonial tanto en el Nuevo Reino como más tarde en el destierro de Italia. En síntesis, se ofrece un modo de adentrarse en futuras investigaciones sobre temas todavía inéditos.

\section{Palabras clave}

Escuela jesuítica. Italia prerromántica. Lugarización. Aportes neogranadinos.

\footnotetext{
* Universidad Católica “Andrés Bello”. Caracas
} 


\begin{abstract}
This paper attempts to design a conceptual map of the contributions of "the local" to the emerging nationalism in the Province of New Kingdom of Granada . It starts with an inventory of production in the area of geo - history which emerges the figure of Italian Felipe Salvador Gilij Saggio di Storia your American (Rome, 1780-1784). Writer best known in European scientific literature of the late eighteenth century, who also knew convene knowledge of many of its conmisioneros. His vision with as yet unpublished authors and Roque Antonio Salillas Lubián is completed. In the history of cartography mentioned Antonio Julián and Joaquín Subías amen of Gilij own. Another important branch is on the Indian Linguistics as polygraph collects Lorenzo Hervás y Panduro in his catalog of the languages of the known nations (Madrid, 1801). A separate chapter deserves the study of the work of the three brothers Julian, Antonio, and Francisco Javier Ignacio, for his excellent contribution to the intellectual assets of the colonial Javeriana University as the New Kingdom and later in exile in Italy. In short, a way of entering into future research on yet unreleased tracks offered.
\end{abstract}

\title{
Key-Words
}

Jesuit School. Preromantic Italy. Lugarización. Contributions neogranadinos.

\section{Recibido: 15 de noviembre de 2013}

Evaluado: 8 de diciembre de 2013 
El año 1767 traza la línea divisoria entre dos fronteras que interpretan dos mundos distintos para los hombres de la Compañía de Jesús en el continente americano: por un lado, el de los que fueron protagonistas de un gran proyecto americano; y por otro, el de los expatriados que miraban con ojos de nostalgia el pasado pero que a la vez necesitaban reafirmar su ideal en medio de la más profunda derelección.

Por ello apelamos al concepto de la "Compañía de Jesús intermedia”, la que tuvo que sobrevivir entre 1767 y 1814, la que amén de sus trágicos avatares existenciales tuvo que realizarse como un ente más que fue arrastrado por el vendaval que tomaría forma de huracán con la Revolución Francesa.

En ese medio siglo de violencias se operó el tránsito del Antiguo al Nuevo Régimen: el primero había perseguido a los jesuitas como seres indeseables para la sociedad ilustrada; y el segundo, el de la revolución, había tratado de aniquilar a los restos que deambulaban como seres anónimos, pero pensantes, por las calles de Europa.

Mas, no todo podía ser pobreza, penurias, tristezas, añoranzas, persecuciones, cárceles y destierros porque también hubo talentos que supieron abrirse paso en un mundo adverso a través de sus actividades científicas, culturales y docentes.

Sin lugar a dudas una excelente imagen de esta situación la ofrece el abate Juan Andrés y Morell (1740-1817) ${ }^{1}$ cuando describía a sus hermanos de religión de la siguiente manera:

“daban compasión tantos hombres de talento y de saber, capaces de ilustrar unos las matemáticas, otros otras ciencias naturales, otros las lenguas muertas, otros las buenas letras, viéndolos destituidos de la comodidad y auxilios necesarios para cultivar sus estudios, y sin poder dar a nuestra nación el honor que ciertamente le acarrearían con sus luces si tuvieran mayores proporciones”2 ${ }^{2}$

El objetivo del presente artículo se cifra en ofrecer una visión sobre el aporte de los jesuitas americanos al concepto de "lugarización” como explicación del tránsito a un nacionalismo emergente.

Dividiremos el trabajo en dos partes. En la primera trataremos de ofrecer una visión general del proceso vivido en el destierro de Italia y en la segunda nos circunscribiremos a la Provincia del Nuevo Reino de Granada.

\section{De la conciencia criolla al nacionalismo emergente}

Si bien es verdad que el mito y la leyenda cubren ciertas áreas de la historia jesuítica en torno a la prestación de los procesos de emancipación de las colonias hispanoamericanas ${ }^{3}$, también es verdad que más allá de las actuaciones políticas de algunos miembros de la Compañía de Jesús existió un intenso cultivo intelectual que fermentó en la literatura y en las ciencias la toma de conciencia entre los expulsos sobre los nuevos conceptos de autonomía y de patria desde el exilio de Europa.

\footnotetext{
1 Batllori, 2001, T.I: 163-165.

2 Cartas familiares..., I, 1786: 5-6.

${ }^{3}$ Véase: Batllori, 1953. Y con otra visión Vargas Ugarte, 1964.
} 
No deja de ser llamativo que al mediar el siglo XVIII Fernando VI diseñara un proyecto de construcción oficial hispana del pasado americano y depositara en la Real Academia de la Historia la responsabilidad de promover esta monumental empresa ${ }^{4}$.

Sin embargo, el fracaso de estos ideales borbónicos lo impedirían en gran parte los jesuitas expulsados por Carlos III de todos sus dominios en 1767 quienes desde su precario exilio italiano poblarían el mundo culto europeo con sus historias locales americanas como testimonio de su aporte a la labor intelectual, científica y cultural desarrollada desde México hasta la Patagonia.

En este contexto nos atrevemos a sugerir, como teoría, que la literatura jesuítica histórica y geo-histórica podría considerarse como el tránsito de la prehistoria a la historia de la conciencia americana y de la conciencia criolla a un nacionalismo emergente.

Fue una curiosa guerra desarrollada en y desde Europa, y lejos de los verdaderos escenarios geográficos. Pero en definitiva fue el ensayo de la búsqueda de lo propio lo que ayudó a la definición de una entidad diferenciada y a la creación de un autoconocimiento identificador ${ }^{5}$. Sin lugar a dudas, los expulsos por Carlos III promocionaron el "regionalismo prenacional" y se les puede considerar como los precursores literarios del nacionalismo americano.

Así pues, si la primera "Escuela jesuítica” se configuró en las aulas de sus universidades colombinas, la segunda recoge la tradición que instauraron los seguidores de Loyola en la construcción de las ciencias de lo que denominaríamos la geo-historia americana.

A la hora de pretender explicar el tránsito de la conciencia criolla a un nacionalismo emergente se olvida en general el peso de una tradición secular jesuítica que consagró sus mejores conocimientos a estudiar e interpretar la América desconocida e irredenta.

La literatura americanista producida por los miembros de la Compañía de Jesús en la primera mitad del siglo XVIII es sencillamente monumental. Todas las regiones continentales se convirtieron en "protagonistas" del sueño americano: era la primera respuesta institucional al reto de la selva y de la precivilización ${ }^{6}$ y por ello proponían meditaciones transformadoras para levantar un nuevo proyecto de la América profunda ${ }^{7}$.

Cuando Manuel Aguirre Elorriaga escribía que la "historia de los grandes ríos americanos está vinculada de modo singular, y por extraña y persistente coincidencia, a grandes misioneros, escritores y descubridores jesuitas" ${ }^{8}$ estaba estableciendo una simetría histórica entre los caminos acuáticos de la geografía americana y la presencia

\footnotetext{
${ }^{4}$ Nava Rodríguez, 1989 y Pagden, 1990.

${ }^{5}$ Osorio Tejada, 1993: 75 y González Stephan, 1993: 30-31.

${ }^{6}$ Indicaremos algunas obras representativas de las regiones más importantes. Venegas, 1757; Kino, 19131922; Ortega, 1754; Lozano, 1733 y Dobrizhoffer, 1784.

${ }^{7}$ Para una visión general: Santos Hernández, 1992: 7-137. Un estudio imprescindible para la geografía histórica jesuítico-venezolana es: Cunill Grau, 1989: 21-68.

${ }^{8}$ Aguirre Elorriaga, 1941: 3.
} 
de miembros de la Compañía de Jesús que supieron legar a la posteridad la biografía de las grandes arterias de los mundos descubiertos por Colón ${ }^{9}$.

Y como la corriente bebe sus aguas de más atrás, conviene mantener como telón de fondo de este contexto la afirmación de Esteve Barba para quien la ciencia geográfica de gran parte del XVII americano corre a cargo de los jesuitas ${ }^{10}$.

Citaremos algunos ejemplos significativos. En el Capitolio de Washington existen dos estatuas representativas de sendos descubridores jesuitas: la del P. Jacobo Marquette (1637-1675) ${ }^{11}$, explorador del Missisipi y la Luisiana ${ }^{12}$ y la del P. Eusebio Kino (1645-1711), descubridor de la Península de California ${ }^{13}$.

En Colombia sería el P. Antonio Julián $(1722-1790)^{14}$ el cantor del gran río Magdalena $^{15}$. La bibliografía sobre el Amazonas ${ }^{16}$ es mucho mayor pues se extiende desde el P. Cristóbal de Acuña (1598-1670) ${ }^{17}$ y Manuel Rodríguez (1628-1684) ${ }^{18}$ pasando por el P. Samuel Fritz (1651-1725) ${ }^{19}$ y Pablo Maroni (1695-1757) ${ }^{20}$ hasta el P. José Chantre y Herrera (1738-1801) ${ }^{21}$.

Y para completar el diseño del semicírculo geográfico misional del subcontinente hay que recurrir a las Misiones del Paraguay. Tanto su rica cartografía ha sido estudiada por el P. Guillermo Furlong ${ }^{22}$ así como la exquisita bibliografía producida por los misioneros guaraníticos como por escritores europeos de todas las épocas ${ }^{23}$.

Pero esta tradición tuvo su continuación en el destierro de Italia con sus características propias pues si en la etapa colonial escribieron sus obras como "trabajo de campo” en las tierras de la península itálica lo harían a la luz de las nuevas corrientes intelectuales.

Son varias las perspectivas desde las que se puede divisar la visión de esta nueva etapa de generación de las ciencias geo-históricas. Sin embargo, juzgamos que lo importante es señalar la importancia que tuvo el estudio de lo local en la gestación de una toma de conciencia sobre el concepto de región y de nación.

\footnotetext{
${ }^{9}$ Mateos, 1944: 109-166.

${ }^{10}$ Esteve Barba, 1965: 636.

${ }^{11}$ Campeau, 2001, T. III: 2514.

12 Marquette, 1855.

${ }^{13}$ Burrus, 2001, T. III: 2194-2195.

${ }^{14}$ Del Rey Fajardo, 2002: 161-167.

${ }^{15}$ Julián, 1787.

${ }^{16}$ Acuña, 1641; Rodríguez, 1684; Fritz, 1707; Maroni, 1889; Chantre y Herrera, 1901.

${ }^{17}$ Fernández G, 2001, T. I: 13.

${ }^{18}$ Villalba, 2001, T. IV: 3398.

${ }^{19}$ Villalba y Domínguez, 2001, T. II: 2194-2195.

${ }^{20}$ Villalba, 2001, T. III: 2511.

${ }^{21}$ Ibíd., 2001, T. I: 751-752.

${ }^{22}$ Furlong Cardiff, 1936. Y una síntesis en: Furlong, 1969: 120-134.

${ }^{23}$ Baptista y Bruno, 2001, T. III: 3032-3038.
} 
Como punto de partida debemos destacar dos factores que impulsaron el cultivo de esa nueva Escuela jesuítica en la Europa de fines del XVIII: la herencia de una tradición centenaria y la respuesta inmediata a las tesis antiamericanistas de ciertos ilustrados europeos que aparecen en torno a la década de los años setenta.

Por una parte, los miembros de la Compañía de Jesús tomaron conciencia de que eran los intérpretes de sentimientos regionalistas que ya se habían arraigado en el espíritu criollo a través de su red de colegios tanto en las grandes urbes como en las provincianas.

El amor por la "ciudad" de los jesuitas coloniales hace años que la detectó el investigador británico David Robinson al reseñar, sobre todo, la añoranza de los ignacianos expulsos de América tras la implantación de la Pragmática Sanción de Carlos III $^{24}$. Y John Lynch destaca a los jesuitas criollos entre los primeros escritores que dotan de expresión cultural al incipiente “americanismo” de la época ${ }^{25}$.

Ello explica que algunos autores consideren a los seguidores de Ignacio de Loyola como precursores de la "lugarización” pues para ésta teoría el mundo es de todos, pero cada una de las partes de ese todo conserva sus rasgos. Estamos ante el nacionalismo planetario ${ }^{26}$.

Un segundo punto de partida proviene de la controversia suscitada en Europa por las tesis sobre la "degeneración de América" proveniente de pensadores ilustrados como el Conde de Buffon, Cornelio de Pauw ${ }^{27}$, François Raynal ${ }^{28}$ o William Robertson $^{29}$, verdadero debate intelectual en el que intervinieron no sólo los jesuitas criollos sino también los españoles y los europeos.

Entre la temática disputada nos fijaremos solamente en la relativa a la tierra y al hombre americanos, es decir, la naturaleza y los indígenas. Sin lugar a dudas, el planteamiento lo ha trazado con toda precisión Antonello Gerbi como "la disputa del Nuevo Mundo" 30 . Y en esta polémica tomaron parte muy activa muchos exjesuitas inmersos en pobreza y destierro frente a la posición oficial diseñada por la Real Academia de la Historia que nunca llegaría a buen puerto ${ }^{31}$.

Si del panorama que abre Antonello Gerbi pasamos a un ensayo de síntesis es aconsejable recurrir a los estudios de Miguel Batllori quien al tratar el tema de la naturaleza americana sugiere dos clases de apologistas: los poetas y los naturalistas, y de seguidas enumera un pequeño grupo. "Entre los poetas latinos sobresalen el guatemalteco Rafael Landívar ${ }^{32}$ y el lusobrasileño José Rodrigues de Melo ${ }^{33}$. Entre los

\footnotetext{
${ }^{24}$ Robinson, 1969: 6-24.

${ }^{25}$ Lynch, 1989: 34.

${ }^{26}$ Véase: González Cruz, 2001.

${ }^{27}$ Pauw, 1771.

${ }^{28}$ Reynal, 1770.

${ }^{29}$ Robertson, 1777.

${ }^{30}$ Gerbi, 1982; Brading, 1991; Peralta Ruiz, 2006.

${ }^{31}$ Nava Rodríguez, 1989.

${ }^{32}$ Landivar, 1781.

${ }^{33}$ Leite, 2004: T. 1: 422-423. Rodrigues de Mello, 1781.
} 
naturalistas, Francisco da Lima para Brasil ${ }^{34}$, Lucas Ventura para California ${ }^{35}$, Hidalgo para México $^{36}$, Philippo Salvatore Gilij para el Nuevo Reino ${ }^{37}$, Antonio Julià para la región del Magdalena ${ }^{38}$. José Sánchez Labrador para el Paraguay ${ }^{39}$, José Jolís para el Chaco $^{40}$, Juan Ignacio Molina para Chile ${ }^{41}$, Gian Domenico Coleti ${ }^{42}$ para toda la América meridional”" ${ }^{\text {"A }}$ A esta escueta enumeración debemos añadir, al menos, dos típicos representantes de estas corrientes: Juan de Velasco $(1721-1792)^{44}$ y sobre todo Francisco Javier Clavigero (1731-1787) ${ }^{45}$ cuya obra $^{46}$ representa la primera "exposición metódica de la civilización indígena y de la aportación europea”47

La lista sobre las aportaciones a los estudios indigenistas sería interminable y por ello remitimos al lector para la parte lingüística a Miguel Batllori ${ }^{48}$ y para la visión de los pueblos indígenas sugerimos al investigador revisar las historias locales de cada uno de los países ${ }^{49}$. Además, una paciente consulta de la Biblioteca jesuítico-española

\footnotetext{
${ }^{34}$ Según Leite, 2004, T. I: 324 siguen inéditos los siguientes libros. A. Dioscorides Brasilicus seu de medicinalibus Brasiliae Plantis. B. De fructibus et rebus naturalibus Brasiliae. C. Descriptio Histórica et Geographica Brasiliae.

${ }^{35}$ El propio Clavigero confiesa que en la parte de la historia natural de su Historia de la antigua o Baja California recibió una gran ayuda de Lucas Ventura. Véase: Gómez F., 2001, T. IV: 3926.

${ }^{36}$ Según Dávila y Arriaga, 1889, T. II: 83, se sirvió de las noticias dejadas por el P. Hidalgo.

${ }^{37}$ Filippo Salvatore Gilij. Saggio di Storia Americana, ossia Storia Naturale, Civile e Sacra dei Regni, e delle provincie Spagnole di Terraferma nell'America meridionale. Scritta dall'Abate Filippo Salvatore Gilij e consacrata alla Santità di N. S. Papa Pio Sesto felicemente regnante. Tomo I. Della storia geografica e naturale della provincia dello Orinoco. Roma MDCCLXXX. Per Luigi Perego Erede Salvioni, Stampatore vaticano nella Sapienza. 8º XLIV-399 pp. Tomo II. De' Costumi degli Orinochesi. Roma, MDCCLXXXI. 8, XVI-399 pp. Tomo III. Della religione e delle lingue degli Orinochesi, e di altri Americani. Roma, MDCCLXXXII. 8, XVI-430 pp. Tomo IV. Stato presente di Terra-Ferma. Roma, MDCCLXXXIV. $8^{\circ}$, XX-498 pp.

38 Julián, 1787. Esta obra formaba parte de una trilogía compuesta por: 1) La Perla de América. 2) El paraíso terrestre en la América Meridional y Nuevo Reyno de Granada. 3) Historia del Río Grande, por otro nombre Magdalena y río Santa Marta... Quedó inédita la Historia geográfica, natural, políticocristiana del río Grande Magdalena, con la demarcación de todos los ríos que en él entran, de las provincias de donde vienen y de las riquezas que acreditan el Nuevo Reino de Granada, el más opulento y rico de las Américas.

${ }^{39}$ Su obra ha permanecido inédita por muchos años pero se agrupa en tres grandes bloques. 1) Paraguay natural ilustrado dividido en tres partes. 2) Paraguay cultivado, 4 partes y un Apéndice. 3) Paraguay Catholico. (Sommervogel, 1896, T. VII: 539-540). Javier Baptista resume el valor de la obra: "Su obra enciclopédica, que no vería entonces la luz, abarca estudios detallados de botánica, zoología, historia, etnología y lingüística, que le colocan entre los más destacados científicos y americanistas” (Baptista, 2001, T. IV: 3492-3493). Para más información véase: Sáinz Ollero, 1989.

40 Jolis, 1789.

${ }^{41}$ Molina, 1782.

${ }^{42}$ Coleti, 1771.

${ }^{43}$ Batllori, 1979: 83.

${ }^{44}$ Villalba, 2001, T. IV: 3919; Velasco, 1981; Navia Méndez-Bonito, 2005: 225-250.

${ }^{45}$ Ronan y Gómez F., 2001, T. I: 824-825; Navia Méndez-Bonito, 2005: 225-250.

${ }^{46}$ Clavigero, 1780-1781.

${ }^{47}$ Goic, 1988, T. I: 489.

48 Batllori, 1951: 59-116.

${ }^{49}$ Una guía informativa puede ser: Baptista, 2001, T. I: 130-133.
} 
de Lorenzo Hervás ilustrará al investigador sobre muchos de esos estudios hoy desconocidos ${ }^{50}$.

También queremos recoger algunos atisbos de lo que significó la gran batalla que dieron los seguidores de Ignacio de Loyola frente a la expansión territorial portuguesa por tierras cercanas al gran Amazonas.

Existe un incidente, al parecer aislado, protagonizado por el franciscano Fr. Francisco Antonio María de Jesús Huerta, procurador y comisario de la Provincia de Quito pero que ilumina los sentimientos de la América profunda en pro de los jesuitas.

Por real cédula del 15 de julio de 1802 se había erigido en obispado los territorios de Mainas pero el franciscano quiteño elevaba su voz de protesta al hacer pasar la jurisdicción del virreintado de Santa Fe al del Perú. Habló con el rey “de la necesidad absoluta de restablecer el ministerio de la Compañía de Jesús en las misiones del Marañón”. Sin embargo, el resultado fue que fue destituido de sus cargos y confinarlo al convento de San Francisco del Monte, en Granada ${ }^{51}$.

\section{Los aportes de "lo local" al nacionalismo emergente en la Provincia del Nuevo Reino de Granada.}

La Provincia del Nuevo Reino de Granada estuvo configurada por las actuales repúblicas de: Colombia, Venezuela y República Dominicana. Opinamos que en sus haberes documentales es la que ofrece más deficiencias y lagunas, y es muy posible que la investigación pueda en un futuro aportar nuevos datos.

Hasta el momento sólo han adquirido cierta importancia a cuatro significativas figuras: Antonio Julián ${ }^{52}$, José Yarza ${ }^{53}$, Felipe Salvador Gilij ${ }^{54}$ y Demetrio Sanna ${ }^{55}$. Sin embargo, en estas líneas trataremos de abrir nuevos rumbos a la investigación moderna.

La geo-historia se enriqueció con diversos aportes y trataremos de seguir sus huellas primero con los autores que han conocido la luz pública a través de la imprenta para hacer alusión después a los inéditos.

A Felipe Salvador Gilij hay que estudiarlo desde las diferentes facetas que ofrece su obra. Y dentro de las provincias de la historia de la cultura hay que resaltar que todo el tomo IV de su Ensayo de Historia americana es una visión histórica, cultural, social y religiosa de Venezuela y Colombia.

El misionero italiano escribe como testigo presencial del auge que vivió en la capital del virreinato en donde estudió las ciencias teológicas y fue profesor de retórica en la Universidad Javeriana. Y también se convierte en actor de un proyecto culturizador en el Orinoco al mediar el XVIII (1749-1767) después de haber conocido y convivido con los actores históricos de esa época ya fuera por sus tareas de Superior de

\footnotetext{
${ }^{50}$ Hervás y Panduro, 2007.

51 Álvarez Arteta, 1901: 452-455.

${ }^{52}$ Del Rey Fajardo, 2006.

53 Ibíd., 2002.

${ }^{54}$ Ibíd., 2006: 311-316.

${ }^{55}$ Ibíd.: 628-630.
} 
la Misión (1761-1765), ya por sus conexiones con los miembros de la Expedición de Límites, ya por las interminables horas de estudio, observación y análisis que conllevó su vida solitaria en la reducción de San Luis de la Encaramada a orillas del río Orinoco.

Estamos ante el juicio de un europeo que ha vivido 26 años en la Tierra Firme y pretende presentar al mundo de habla italiana una idea justa de la Orinoquia y de la Tierra Firme, ya que, a su juicio, muchos autores europeos habían deformado y alterado su verdadera imagen ${ }^{56}$.

Gilij no es un historiador tradicional. El impacto de la vida europea de fines del XVIII le hace transitar nuevas perspectivas científicas que completan de forma impecable. Da por supuesto lo escrito por la historia jesuítica, sintetizada en Cassani y la visión introductoria de la antropo-geografía orinoquense ofrecida por Gumilla. Lo histórico, como crónica, lo remite a la obra de Gumilla $^{57}$-que por cierto la cita de la traducción francesa-. Pero en todo lo que atañe a la Orinoquia procura hacer referencias a los principales autores que trataron la temática por él estudiada ${ }^{58}$.

En verdad, con el Saggio di Storia Americana (Roma, 1780-1784) se completa el ciclo historiográfico de autores jesuitas que escribieron sobre la Orinoquia durante el período hispánico. Y no deja de ser curioso que esta disciplina se inicie con el francés Pedro Pelleprat en 1655 y se concluya con el italiano Felipe Salvador Gilij en 1784.

Si El Orinoco ilustrado es la primera interpretación venezolana de la Orinoquia para los europeos el Saggio di Storia Americana se puede considerar como una de las primeras visiones de nuestro mundo escrita para los hombres del viejo mundo que pretenden reinventar la historia de nuestras tierras y nuestros hombres.

El estudio del Saggio no ofrece lugar a dudas: el autor intenta ser el portavoz del silente mundo indígena orinoquense ${ }^{59}$ falto de buenos estudios. Pero aunque el fin principal sea el indígena orinoquense, debemos insistir todavía en la existencia de un

\footnotetext{
${ }^{56}$ Gilij, 1965, T. I: 45. "El prurito de formar libros sobre cosas no bien comprobadas ha inducido a no pocos a tejer una fábula sobre las comarcas de América". Gilij, 1955, T. IV: XIX. "Y esta mía... no tiene otro fin que el de dar a muchos que me lo han pedido una justa idea de los países americanos, idea ahora necesaria para conocer bien esta parte del mundo, años atrás tan alterada y aun deformada por la exageración o por las falsedades..."

${ }^{57}$ Gilij, 1965, T.II: 228.

${ }^{58}$ En realidad Gilij conoció la principal bibliografía sobre la Orinoquia. A cada paso cita El Orinoco ilustrado en su versión francesa. La Condamine. Voyage à l'Amérique Meridional (Gilij, 1965, T. I : 44). Lucas Fernández de Piedrahita (Idem, I, 138). La Chronica de Torrubia (Idem, I, 139). La Historia Chorographica de Caulín (Idem, I, 284). La Historia de Oviedo y Baños (Idem, IV, 135).

${ }^{59}$ Gilij, 1965, T. II: 23. "Mi historia tiene por objeto principalísimo los indios...". Gilij, 1965, T. II: 15: "Si se pudiera hablar de los indios de aquella manera en que se habla de las naciones o más civilizadas o más conocidas. Y ellos tuvieran también escritores que pusieran de manifiesto con libros sus méritos, después de tantos años de los descubrimientos de Colón estaría al fin acallado o resuelto el pleito que aún se agita con fervor sobre el mérito de ellos. Pero la causa de los indios, al contrario de la de las otras naciones, nunca ha sido ni ilustrada ni promovida con argumentos sólidos por aquellos que eran parte en ella. En el decurso de tantos años, en tiempo tan largo, jamás ha aparecido nadie que, poniéndose a la cabeza de sus compatriotas, haya defendido o propalado sus prerrogativas. Estén sujetos a los españoles, lo estén a los franceses o ingleses y a otras naciones europeas, los indios todos... son por lo general ignorantes, a modo de campesinos, son pobres no menos de fortuna que de talentos y espíritu". Gilij, 1965, T. II: 16: "Queda pues que la causa de los indios, privada como la de los campesinos, de protectores propios, se vuelva para su defensa a los extraños. Pero cuán raros son los que logran la justa medida. Algunos, como abogados seducidos por afan de partido o por falta de luces justas, los rebajan hasta el extremo. Otros por el contrario, los alaban, pero sin discrección...".
} 
trasfondo real que hace relación directa a un marco de referencia: escribir en su lengua materna la historia de la Compañía de Jesús en el gran río venezolano ${ }^{60}$.

Pensamos que en la mayoría de los casos, el núcleo de su argumentación radica en su concepción del autóctono o en la matización de teorías como la del buen salvaje y otras de diversa índole científica. Por ello hay que examinar en cada caso el hecho profundo y no la persona que representa la contienda, ya sea Buffon, Voltaire, de Pauw, Raynal, Marmontel y Robertson, ya sean hermanos suyos en religión como el chileno Molina $^{61}$. Y una interesante síntesis de las polémicas, en su globalidad, las ha planteado Antonello Gerbi ${ }^{62}$.

Y su obra histórica se completaría con otros estudios que hoy aparecen como perdidos. Nos referimos a las Anécdotas americanas $^{63}$ y la Religión de los americanos $^{64}$.

Dentro de la historiografía jesuítica se citan dos obras, todavía inéditas, para la biografía de la Orinoquia: y la Historia natural del Orinoco debida a la pluma del P. Antonio Salillas ${ }^{65}$ y la Historia del Orinoco escrita por el P. Roque Lubián a la que habría que añadir el Apéndice a la Real Expedición de límites entre los dominios de España y Portugal en América.

Llegamos al conocimiento de estos dos últimos escritos gracias a la reseña que les otorga Hervás y Panduro en su Biblioteca jesuítico-española ${ }^{66}$. Sin embargo, conviene precisar algunas de sus afirmaciones. Dice Hervás que Lubián "dejó en América los siguientes manuscritos que tenía dispuestos para la impresión" ${ }^{67}$. En realidad esta afirmación no creemos que se ajuste a los hechos. En los inventarios levantados en la reducción de San Miguel de Macuco al momento del extrañamiento no aparecen tales manuscritos $^{68}$ y si existieron no son los que en el destierro de Roma redactó el misionero orinoquense.

La hipótesis formulada -al menos para la Historia del Orinoco- tiene su confirmación en el testimonio del P. Antonio Julián, quien al respecto afirma desde su destierro italiano:

\footnotetext{
${ }^{60}$ Gilij, 1955, T. IV: 280: "Cada Orden, como dije en otra parte, se ha preocupado suficientemente por hacer su historia: Zamora la de los dominicos, Simón la de los franciscanos, Cassani la de los jesuitas que ya no se encuentran allá: todos ellos escribieron en español. Hasta ahora no hay sobre este tema historia alguna en nuestro idioma, por lo tanto no debe desagradar que yo trate brevemente de él...".

${ }^{61}$ Hanisch, 1976.

${ }^{62}$ Gerbi, 1960: 204-214.

63 Gilij, 1965, T. III: 336: "Las restantes noticias, si a Dios place, se añadirán separadamente en las Anécdotas americanas”. Y en el T. IV (: 75) añadirá: “Pero de este asunto hablaré en mejor ocasión, es decir, cuando en tomo separado publique mis Anécdotas Americanas”.

${ }^{64}$ Ibíd.: 50: "Pero hemos dicho bastante de la religión antigua de los orinoquenses. Cosa ciertamente grata sería oir ahora las máximas de otros americanos sobre este punto; y nosotros, si Dios nos da tantas fuerzas, lo haremos en volumen separado". Y en el T. IV (: 218) vuelve sobre el tema: "Y basta por ahora haber dicho esto acerca de un punto al cual deberé volver más detenidamente en el tomo que prometí sobre la Religión antigua americana”.

${ }^{65}$ AIUL, Papeletas: Salillas, Antonio.

${ }^{66}$ Hervás y Panduro, 2007, T. I: 343-344.

${ }^{67}$ Ibidem.

${ }^{68} \mathrm{El}$ inventario reposa en: ANB. Conventos, t. 34, fols., 805-808.
} 
Y para que no vacile el lector sobre la verdad de lo referido, concluyo con asegurar al público que todo cuanto he producido y queda dicho de los extranjeros en el Orinoco alto y bajo en estos dos discursos preliminares, todo lo he sacado de la historia del Orinoco, que en cuadernos manuscritos (que tengo en mi poder) dejó en la hora de su muerte a un amigo mío (nota: El señor don Manuel Balzátegui, sujeto de probada virtud, integridad y doctrina, que fue por muchos años superior y depositario de los santos designios de Lubián) el señor abate don Roque Lubián, antiguo misionero del Orinoco y Meta, en la que fue Provincia de Santa Fe; varón de probadísima virtud y sinceridad apostólica, honor del reino de Galicia y operario insigne en aquellas misiones por más de cuarenta años continuos; compañero e íntimo confidente del famoso padre Manuel Román, de cuya boca también hemos oído, muchos que al presente vivimos, estos mismos y semejantes trágicos sucesos ${ }^{69}$.

Ciertamente que esta redacción no fue hecha en suelo americano sino que pertenece ya a la época del exilio. Hasta el momento no hemos logrado obtener noticia alguna del paradero de los "cuadernos manuscritos" que vendrían a clarificar una zona temporal, todavía no escrita, sobre la acción jesuítica en el gran río venezolano.

De gran utilidad para la historiografía colombo-venezolana del siglo XVIII sería el libro Apéndice a la Real Expedición de límites entre los dominios de España y Portugal en América. La forma de describir Hervás su información nos lleva a la conclusión de que tampoco conoció directamente este manuscrito sino que su información es indirecta. En todo caso, la existencia del documento parece factible aunque por el momento no dispongamos de ninguna confirmación de tan interesante libro.

Una prueba indirecta con respecto a la redacción de estos escritos nos la ofrece el agustino fray Pedro Cuervo cuando declaraba en el Puerto de Casanare el 20 de mayo de 1817 ante el Presbítero José María Vargas, el contenido del archivo que habían sustraído de Macuco, residencia del P. Roque Lubián, y que no había sido recensada por los inventarios de $1767^{70}$.

Un capítulo aparte merecería el estudio de la obra de los tres hermanos Julián, Antonio, Ignacio y Francisco Javier, por su excelente aporte a los haberes intelectuales de la Universidad Javeriana colonial tanto en el Nuevo Reino como más tarde en el destierro de Italia.

Antonio cruzaría el Atlántico el año $1749^{71}$ como miembro de una expedición solicitada por la corona hispana con la tarea gubernamental de encargar la misión de la Guajira a los jesuitas neogranadinos ${ }^{72}$ mientras que Ignacio lo haría en $1760^{73}$ y Francisco Javier un año después ${ }^{74}$.

Lo llamativo de este trío es que Antonio recibiría su formación en el Colegio de Nobles de Barcelona ${ }^{75}$ mientras que sus dos hermanos serían fruto de la Universidad de

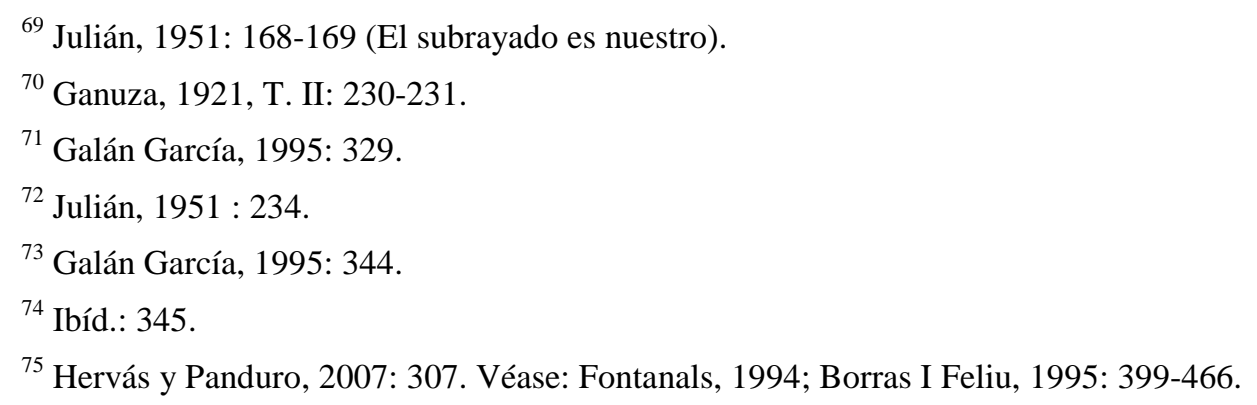

13 José Del Rey Fajardo SJ. La olvidada “Escuela Jesuítica” en la Italia prerromántica ... 3-33. 
Cervera ${ }^{76}$ verdadero centro universitario abierto a las nuevas corrientes intelectuales. Lamentablemente la expulsión de 1767 truncó las esperanzas de renovación literaria que hubieran podido aportar estos egresados de esta universidad catalana.

Sin lugar a dudas Antonio Julián fue una de las plumas más fructíferas de los miembros de la Compañía de Jesús neogranadina. El bibliófilo Hervás y Panduro, amigo del profesor de la Universidad Javeriana escribirá: "En Italia vivió siempre con los libros a la vista y en ejercicios de religión. Los graves achaques que padeció por algunos años antes de morir, no le impidieron hacer el estudio que solamente convendría al hombre más sano" ${ }^{77}$.

El más desconocido hasta el momento es el segundo de los hermanos: Ignacio. Antes de ingresar a la Compañía de Jesús había estudiado Filosofía, Leyes y Cánones e incluso había sido profesor de la Universidad de Cervera ${ }^{78}$. La expulsión le sorprendió en Maracaibo cuando se disponía a pasar a la Isla de Santo Domingo como profesor de la Universidad de Gorjón ${ }^{79}$. Lamentamos el no poder disponer de documentación sobre sus años de exilio italiano.

Si Antonio fue ante todo un escritor teólogo e Ignacio un canonista, Francisco Javier se consagraría como consumado humanista en el sentido más amplio del concepto y casi viene a representar una reencarnación intelectual de su hermano Antonio. Toda su producción intelectual se realizaría desde el destierro en la península itálica. La ejecución de la Pragmática sanción (2 de abril de 1767) lo encontró en el colegio de Mompox

Gracias al polígrafo Lorenzo Hervás y Paduro podemos reseñar su abundante producción escrita. Conviene distinguir en su bibliografía varios campos temáticos.

En el de las humanidades clásicas señalamos: Pluto deiectus: vel destructio Erebi $^{80}$; Merx nova entium virtualium ab Europa nuper in Americam advecta ${ }^{81}$; Anacreonte traducido en español con explicación de sus palabras para uso de los que estudian lengua griega ${ }^{82}$.

\footnotetext{
${ }^{76}$ Hervás y Panduro, 2007: 615.

${ }^{77}$ Ibíd.: 308.

78 AHN. Jesuitas, 827/2. Filiacion de los Regulares de la Compañia transferidos de la Provincia de Santa Fee de Bogotá en el Navio nombrado San Pedro y San Pablo que al presente se hallan recidiendo en la Casa Hospicio de esta ciudad. No. 178: “178: El Padre Ygnacio Julian natural de la villa de Camprodo en el Principado de Cataluña, (...) haviendo estudiado la Philosophia, Leyes y Canones, el de setecientos sinquenta y sinco, en la Provincia de Aragon, tubo su Noviciado en Torrente, y Tarragona, Maestro de Grammatica en la Real Universidad de Cervera, paso a la America, en Micion, que se embarco en la Bahia de la Ciudad de Cadíz”.

${ }^{79}$ ANCh. Jesuitas, 205. Santa Fee. MARACAIBO. AÑO DE 1767. Santa Fee. Legajo 9. No 1. Son con esta 4 piezas. El Gobernador Don Alonso del Rio sobre Remision de Autos de expulsión y ocupacion de templos de Regulares de la Compañia. Secretario de Camara. Payo, fol., 9v.

80 “Tragedia latina” (Hervás y Panduro, 2007: T. I: 616.

81 “Obra cómica” (Ibíd.: 616).

${ }^{82}$ Ibíd.
}

14 José Del Rey Fajardo SJ. La olvidada “Escuela Jesuítica” en la Italia prerromántica ... 3-33. 
En el área filosófica tenemos noticia de: Curso filosófico ${ }^{83}$ en cinco tomos. Quizá podríamos incluir aquí el Scholasticus Societatis Iesu practice instructus ${ }^{84}$. Y en la teológica: Summa Theologiae scholasticae uno volumine comprensa ${ }^{85}$.

Dentro de lo que podríamos señalar como ciencias divinas hay que añadir: Parafrasi de los salmos de David ${ }^{86}$ y el tema tan debatido en el siglo XVII: Systema Molinae circa concordiam gratiae divinae cum libero arbitrio ${ }^{87}$. Y dentro del ámbito de la teología espiritual todavía conviene incluir sus Meditaciones breves ${ }^{88}$.

Como temas libres son interesantes La sovranitá pontificia: ossia opera sopra el dominio temporale del $\mathrm{Papa}^{89}$ y la Traducción española de la obra de Wallerio sobre el origen del mundo y particularmente de la tierra ${ }^{90}$. Se trata de Johann Gottschald Wallerio (1709-1785) autor de Systema Mineralogicum quo corpora Mineralia in Classes, Ordines, Genera et Species suis cum varietatibus. Divisa, Describuntur atque Observationibus, Experimentis et Figuris aeneis illustrantur a Johan. Gottsch. Wallerio. Holmiae. Impensis e Det. Direct. Laurentii Salvii. (1772-1775).

Este interesante panorama literario se cierra con una intensa actividad epistolar con algunos organismos de la Santa Sede como lo recoge el P. Manuel Luengo en su Diario en una extensa nota que le dedica el día 7 de junio de $1776^{91}$. Los bibliófilos Uriarte y Lecina han recogido en sus notas una síntesis de este complicado proceso: Memorial presentado por el Sr. D. Javier Julián al Emmo. Cardenal Juan Bautista Rezzonico en nombre de los Exjesuitas españoles, pidiendole se sirviera alcanzarles algunas gracias de Su Santidad ${ }^{92}$. Y Carta del P. Xavier Julián desde Roma al P. Fco. Xavier de Idiáquez, con noticia de gracias de indulgencias y rezo de los Santos de la Compañía y de los de España, y del modo con que las sacó ${ }^{93}$.

Quizá ha tenido más difusión en el ámbito colombiano la extensa obra del que fuera un insigne catedrático de la Universidad Javeriana Antonio Julián por su obra clásica La Perla de América. Provincia de Santa Marta ${ }^{94}$.

En la concepción juliana su historia se componía de una trilogía cuyo material lo envió a Madrid para que fuera publicado por don Antonio Sancha. Sin embargo, sólo conoció la luz pública La Perla de América. Las otras dos permanecieron inéditas. La

\footnotetext{
${ }^{83}$ Ibíd. "El autor ha envido a Madrid esta obra, escrita en lengua latina".

${ }^{84}$ Ibíd.

85 Ibíd.

${ }^{86}$ Ibíd.

${ }^{87}$ Ibíd.

${ }^{88}$ Ibíd.

${ }^{89}$ Ibíd.

90 AIUL. Papeletas: “Julián, Francisco Javier”: “Traducción española de la obra del Origen del mundo y particularmente de la tierra, del celebre Wallerio, Profesor de mineralogía en Upsal, con notas y un discurso preliminar” (que envió a la Academia Real Barcelonesa, y que es posible que se imprimiera).

${ }^{91}$ Luengo, Diario, 7 de junio de 1776.

92 AIUL. Papeletas: “Julián Francisco Javier”: en fol., 2 h.

93 Ibid. Papeletas: “Julián, Francisco Javier”: "Papeles Luengo, tomo V”.

94 Julián, 1787. Esta obra ha conocido otras tres ediciones, además de la madrileña: una en París en 1854 y dos en Bogotá: 1951 y otra facsimilar: Bogotá. Academia Colombiana de la Historia, 1980.
} 
segunda era El paraíso terrestre en la América meridional, y Nuevo Reino de Granada. Un tomo en $8^{\circ}$ con 15 discursos ${ }^{95}$. La tercera obra se intitula: Historia del río Grande: por otro nombre Magdalena, y río de Santa Marta ${ }^{96}$.

Pero la actividad histórica del jesuita neogranadino fue grande. Dos libros aparecieron en Italia en 1790. El primero: Dissertazione critico-espositiva sopra una parte del capitolo 3 della Epistola 2 di S. Pietro. Roma, $1790^{97}$ y el segundo: Trasformazione Dell America ossia Trionfo Della S. Chiesa Sulla Rovina della Monarchia del Demonio in America Dopo La Conquista Fattane Da' Monarchi Della Spagna $^{98}$. Hay que dejar anotado que la traducción castellana de esta obra apareció en 1994 en Bogotá99.

No conoció la luz pública el manuscrito Storia apologetica dei guasti e pregiudizi cagionati dalle Nazioni Straniere alla Nazione e Monarchia Spagnola ${ }^{100}$.

Dentro del género histórico sería vital conocer las Historias útiles en que el autor impugna algunos puntos de la Historia de Gilij ${ }^{101}$ que recoge la polémica del $\mathrm{P}$. Antonio Julián contra el P. Felipe Salvador Gilij. Y del mismo autor Sommervogel hace referencia a Obra sobre la conversión, costumbres de los americanos, etc. ${ }^{102}$.

\footnotetext{
95 Hervás y Panduro, 2007, T.I: 309. El manuscrito original reposaba en manos de Ezequiel Uricoechea (Uricoechea, 1872: 203. Véase: Romero, 1994: 14-15.

${ }^{96}$ Antonio Julián. Historia del río Grande: por otro nombre Magdalena, y río de Santa Marta; con la descripción individual de todas las provincias del nuevo reino de Granada que baña con sus corrientes y les tributa sus aguas y de todas las minas, corrientes de oro y plata, otros metales, piedras preciosas, ramos de comercio y singulares producciones de la naturaleza". Tres tomos en $8^{\circ}$. El primer tomo contiene 30 discursos. La obra se acompañará con una planta exactísima del puerto de Santa Marta y con un mapa original, el más correcto e individual de las provincias del Nuevo Reino. (Hervás y Panduro, 2007, T. I: 309). Obra citada por el propio Julián (1787: 247). Sommervogel, 1896, T. IV: 868, lo da como impreso y especifica: "Madrid, 178..., 8º 3 vol.".

${ }^{97}$ Antonio Julián. Dissertazione critico-espositiva sopra una parte del capitolo 3 della Epistola 2 di S. Pietro, che discopre aver GesuCristo visitato e predicato alle genti americane prima della sua ammirabile ascensione al cielo. Roma, 1790 (Hervás y Panduro, 2007, T. I: 309).

98 Antonio Julián. Trasformazione Dell America ossia Trionfo Della S. Chiesa Sulla Rovina della Monarchia del Demonio in America Dopo La Conquista Fattane Da' Monarchi Della Spagna: Con Riflessioni Apologetiche, e coll' aggiunta di una Dissertazione Critico-Espositiva, nella quale spiegandosi le parole di S. Pietro Epi I. c. 3. Qui increduli fuerant in diebus Noe, cum fabricaretur Arca $v v .18,19,20$. Dimostrasi con valide ragioni, essere tutto ció accaduto nell'America. Opera Del Sacerdote Antonio Julián per molti anni Missionario in quelle parti. In Roma, MDCCXC. (Streit, 1927: 327). Según Streit se encuentra la Dissertazione Critico-Espositiva en las páginas 239-282 de este libro. Cfr. Effemeridi Letterarie di Roma, t. 19, pp. 385-386.

99 Antonio Julián, 1994. El verdadero título es: Monarquía del diablo en la gentilidad del Nuevo Mundo Americano derribada y destruída por los Católicos Monarcas de España: Triunfos de la religión en los dominios conquistados con la fe, valor y armas de los españoles: con reflexiones para confundir a los anticatólicos mordaces émulos de la nación española benemérita de todas las naciones del orbe en conquista tan gloriosa. Historia interesante a la Religión y Monarquía. Compuesta por don Antonio Julián ex-Jesuita. El Manuscrito se encuentra en la Biblioteca de la Universidad de Yale. Mss. 154.

100 Antonio Julián. Storia apologetica dei guasti e pregiudizi cagionati della Nazioni Straniere alla Nazione e Monarchia Spagnola della Terra Ferma e in tutta America Meridionale soggetta al Monarca Catolico. (Sommervogel, 1896, T. IV: 868; Quevedo, 1952: 257.

101 Sommervogel, 1896, T. IV: 868. A.

102 No sabemos si se trata de una obra nueva o de alguna de las mencionadas más arriba.
} 
En un ámbito más general debemos incluir al excatedrático de la Universidad Javeriana y miembro del colegio jesuítico de Caracas el P. Jaime Torres $(1711-\dot{¿} \text { ? })^{103}$ quien en el destierro tradujo la Historia de la Iglesia en el Japón del P. Crasset y la dejó manuscrita ${ }^{104}$.

Otra huella histórica para seguir la actividad de los expatriados y después de 1773 exjesuitas son las clásicas notas mortuorias que se escribían a la muerte de cada miembro de la Compañía de Jesús. Solamente dos hemos conocido hasta el presente relativos al Nuevo Reino. La primera se debe a la pluma del P. Manuel Balzátegui quien redactó la necrología del misionero orinoquense Roque Lubián fallecido el 8 de mayo de $1781^{105}$. Y la segunda pertenece al P. Manuel Padilla sobre el P. Andrés Villa, muerto en Pérgola a 12 de abril de $1775^{106}$. Sin embargo, también hubo neogranadinos que ofrecieron su pluma para otros correligionarios como es el caso del P. Jaime de Torres y su biografía de Juan Saloni [Salom] muerto en el Paraguay ${ }^{107}$.

No podemos dejar de lado la escasa literatura que produjo la Provincia del Nuevo Reino con respecto a los escritos que recogen la expulsión de 1767: hasta el presente ha conocido la luz pública el Diario del P. José Yarza ${ }^{108}$ y sigue inédito el del P. Ignacio Duquesne ${ }^{109}$.

$\mathrm{Al}$ acceder al tema de la geografía hay que apelar de nuevo a Felipe Salvador Gilij y al catedrático javeriano Antonio Julián.

Antes de entrar al aporte gilijiano a la geografía orinoquense es necesario hacer alusión a la estructura mental del P. Gilij para poder entender la equilibrada simbiosis de sus concepciones de Europa y América. Los estudios superiores -humanidades, filosofía y teología- responden a tres centros distintos: el colegio Romano bajo la dirección del P. Juan Bautista Faure ${ }^{110}$; el colegio de San Hermenegildo de Sevilla,

\footnotetext{
${ }^{103}$ Del Rey Fajardo, 2006: 700-703.

${ }^{104}$ Jaime Torres. Traducción española de la <Historia de la Iglesia del Japón> publicada en francés por el jesuita Juan Crasset. En 4 tomos (Mss.). Véase: Hervás y Pandur, 2007, T. I: 535. En AIUL. Papeletas: Torres, Jaime, se añade: “con algunas notas y aclaraciones”.

${ }^{105}$ Manuel Balzategui. Noticia de la vida, virtudes y trabajos del apostólico varón Padre Roque Lubian que, después de 40 y más años de misionero del Orinoco y Meta, murió en destierro de Italia y Gubbio 8 de mayo de 1781. En: Uriarte y Lencina, 1925: 416: "En 4º 18 hs.".

${ }^{106}$ Manuel Padilla. Vida del P. Andrés Villa que murió en Pérgola a 12 de abril de 1775. En $4^{\circ}$. "En AIUL. Papeletas: PADILLA, Manuel. A todas luces comete un error cronológico el P. Hervás (Hervás y Panduro, 2007, T. I: 649) al afirmar que el texto se "Imprimió en América: Vida del jesuita Andrés Villa". 107 Torres, 1763.

108 Expulsio sociorum, 1767. Narratur historia laborum Societatis inter Indianos, quorum indoles et mores discribuntur. Iter exsulium Jesuitarum in Italiam. Suppressio Societatis. 1773. El original se encuentra en el ARSI y una mano posterior le colocó el título antes descrito. El Ms. consta de 59 folios de los que los 40 primeros están consagrados a una descripción del Nuevo Reino de Granada y de sus habitantes. La segunda parte fue publicada por el P. Juan Manuel Pacheco en Revista Javeriana, 38 (1952) 170-183. También nosotros lo reeditamos en: Documentos jesuíticos para la Historia de la Compañía de Jesús en Venezuela. Caracas, Academia Nacional de la Historia, III (1974) 73-90. Pensamos que es la misma obra que cita Sommervogel (Bibliothèque, VIII, 1357) en castellano. Hervás y Panduro, 2007, T: I: 694.

109 Ignacio Duquesne. Relazione sopra il viaggio dei Gesuiti Della Provincia di Sta. Fede di Bogotá. (APT. Leg., 700).

${ }^{110}$ Gilij, 1955, T. IV: 265.
}

17 José Del Rey Fajardo SJ. La olvidada “Escuela Jesuítica” en la Italia prerromántica ... 3-33. 
lugar de encuentro de todos los jesuitas europeos que viajaban a América ${ }^{111}$ y la Universidad Javeriana de Bogotá. Este ciclo académico se completaría con la experiencia y la reflexión misional y con el estudio de los adelantos de la ciencia europea a su retorno a Italia.

El primer volumen del Ensayo de Historia americana está dedicado a la historia natural (zoología y botánica) pero el acucioso lector también descubrirá un tesoro de pequeñas noticias históricas, geográficas, biográficas y misionales. Un concienzudo esbozo de Gilij como geógrafo ilustrado de visión holística la ofrece Pedro Cunill Grau: "Felipe Salvador Gilij fue un humanista dieciochesco que con esta obra quiso dar luces al conocimiento de tierras y aguas orinoquenses, proyectándolas hacia el futuro para su adecuado poblamiento y movilización cuidada de sus recursos naturales. Se inserta entre los geógrafos ilustrados que con nuevo lenguaje científico intentaron fomentar diversas utilizaciones de las materias primas de la naturaleza, evaluar las consecuencias de aclimataciones y transculturaciones de hombres y recursos, incentivar acciones de poblamiento y embellecimiento u ordenamiento de los paisajes silvestres por paisajes armónicos, urbanizados. Además, con racionalidad intentó que sus aportes fueran utilitarios” ${ }^{\prime 12}$.

El impacto de su obra en el mundo europeo y sobre todo en el alemán se echa de ver en las traducciones casi simultáneas que tuvo su obra. Así nos consta de la de Kart E. Bohn, Nachrichten vom Lande Guiana, dem Orinocoflus, und den dortigen Wilden $^{113}$, y las de Francisco Javier Veigl: Nachrichten der Völker am Orinokoflusse ${ }^{114}$. Posteriormente sería utilizado por Alejandro de Humboldt en sus descripciones e interpretaciones de la cuenca del Orinoco ${ }^{115}$.

Para una comprensión global del aporte del misionero de la Encaramada a la geografía venezolana nos remitimos al interesante estudio del académico Pedro Cunill Grau $^{116}$.

Pero también queremos resaltar que la Guayana profunda se hace presente en la Europa no hispana a través del misionero orinoquense y para ello utiliza los mejores diccionarios geográficos de esa época: la Encyclopedie de Diderot y D’Alembert ${ }^{117}$; el

\footnotetext{
111 AHN. Jesuitas, 827/2. Filiacion de los Regulares de la Compañia transferidos de la Provincia de Santa Fee de Bogotá en el Navío nombrado San Pedro y San Pablo que al presente se hallan residiendo en la Casa Hospicio de esta Ciudad.

112 Cunill Grau, 1989: 25.

${ }^{113}$ Nachrichten vom Lande Guiana, dem Orinocoflus, und den dortigen Wilden. Aus dem Italienischem des Abbt Philip Salvator Gilii Auszugsweise übersetzt. Hamburg, bei Carl Ernst Bohn, 1785. El libro fue publicado por M. C. Sprengel y consta de XVI-528 pp.

${ }^{114}$ Nachrichten der Völker am Orinokoflusse. Aus dem Saggio di Storia Americana des Herrn Abbate Filippo Salvatore Gilij vormaligen Missionars am Flusse Orinoko, gedruckt zu Rom 1782. Ins deutsche übersetzt, mit einigen Verbesserungen vom Herrn Abbé Franz Xavier Veigl. Forma parte de la obra de Christoph Gottlieb von MURR. Reisen einiger Missionarien der Gesellschaft Jesu in Amerika. Aus ihren eigenen Aufsätzen herausgegeben von Christoph Gottlieb von Murr. Mit einer Landkarte und Kupfern. Nürnberg, bei Johann Eberhard Zeh, 1785, pp. 325-404. [Evidentemente se trata de la traducción del Tomo III del Saggio]. Según Streit (Bibliotheca Missionum, III, 344) el mismo P. Veigl hizo una segunda edición en 1798 y en la página 314 se refiere a una traducción latina de la que no poseemos ninguna otra noticia.

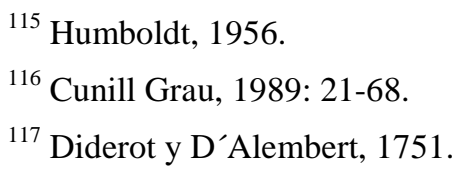


Dictionnaire raisonné universel d'histoire naturelle de Bomare ${ }^{118}$; la versión francesa de Laurence Echard, el Dictionnaire geographique-portatif ${ }^{119}$ y el Dizionario storicogeográfico dell'America Meriodanale del P. Juan Domingo Coleti ${ }^{120}$.

No es la cartografía el fuerte de Gilij y creemos que por una razón muy sencilla, pues, durante su estancia misionera en el Orinoco la Expedición de Límites tuvo como una misión específica el levantar mapas de todas esas regiones y a ellos se remite el jesuita italiano: "Por lo que hace al Orinoco, de buena gana adornaría este libro mío con las observaciones de los señores de la Real Expedición de Límites, que tuvieron consigo astrónomos y geógrafos excelentes”121.

En dos puntos insiste Gilij a la hora de precisar su mapa. Primero, en fijar las coordenadas de las bocas del Orinoco, las de la población de Cabruta y las del Raudal de Atures. Segundo, en dilucidar si las fuentes de nuestro gran río están en la Parima ${ }^{122}$.

También es de justicia señalar los colaboradores del autor del Ensayo de Historia americana, dedicada a la Tierra Firme.

El P. Manuel Collado (1714-1800) fue un buen conocedor de la región zuliana y a su pluma le debería valiosas informaciones contenidas en la Descripción de las Gobernaciones de Maracaibo, Santa Marta y Popayán ${ }^{123}$. Expulsado a Italia vivía en Scapezano en $1774^{124}$. Murió en Urbino a principios de $1800^{125}$. Para la Provincia de Caracas se servirá de "los preciosos informes" que le remitió el P. José $M^{a}$ Forneri (1719-¿ं?) quien vivió 10 años en la capital venezolana ${ }^{126}$. Y para la región de San Juan de los Llanos apelará a los datos suministrados por el P. Antonio Salillas (1717$1790)^{127}$. No especifica en el texto las "preciosas noticias" que le debe al P. Jaime de Torres que dividió su biografía americana entre Bogotá y Caracas ${ }^{128}$ y después a ser

${ }^{118}$ Valmont-Bomare, 1764.
${ }^{119}$ Echard, 1779.
${ }^{120}$ Coleti, 1771.
${ }^{121}$ Gilij, 1965, T.I: 23-24.
${ }^{122}$ Ibíd.: 24.
${ }^{123}$ AIUL, Madrid. Papeletas: Collado, Manuel. "En 4º 80 hojas". El propio P. Gilij (1955: T.IV: XX) dice: "... luego al P. Juan Manuel Collado muy conocedor de la Tierra Firme, pero especialmente de los gobiernos de Maracaibo, Santa Marta y Popayán". Esto nos hace pensar que posiblemente fue destinado a Coro en 1756 pero en realidad su destino real fue Maracaibo, y así lo declaraba el P. Collado el 5 de mayo de 1768 en el Puerto de Santa María (AHN. Jesuitas, 827/2. Filiacion de los Regulares de la Compañia transferidos de la Provincia de Santa Fee ... que al presente se hallan en la Casa Hospicio de esta ciudad. $\mathrm{N}^{\mathrm{o}}$. 147).

${ }^{124}$ ANCh. Jesuitas, 442.

${ }^{125}$ Archivo de Monumenta Historica Societatis Jesu. Armadio F-10. Archimbaud. Relacion individual de los Ex-jesuitas muertos de las Once Provincias de España e Indias desde la expulsión hasta el día 30 de junio de 1777. Por Don Juan Antonio de Archimbaud. Provincia del Nuevo Reino de Granada. Nº 4465.

${ }^{126}$ Gilij, 1955: XX: “... del primero [Forneri] obtuve los más preciosos informes sobre la Provincia de Caracas en la que vivió algunos años”.

${ }^{127}$ Ibíd.: “... y del otro [Salillas] datos sobre los Llanos de San Juan donde estuvo de misionero de los Amarizanos antes de venir al Orinoco”

128 Ibíd.: "Viene luego aquel que por sus singulares talentos debía ser el primero, a saber, el Padre Santiago [Diego] de Torres, mi maestro de Teología allá en Santafé del Nuevo Reino a quien debo preciosas noticias”. 
Procurador General en Madrid de las Provincias del Nuevo Reino y Quito. El P. Enrique Rojas (1729-¿¿ ? $^{129}$ le suministró los datos del Corregimiento de Tunja ${ }^{130}$.

Pero al margen de las colaboraciones anteriormente descritas debemos hacer referencia a un interesante manuscrito del P. Antonio Salillas ${ }^{131}$, buen conocedor da los acontecimientos históricos que se desarrollaron en nuestra gran arteria fluvial pues trabajó con los amarizanos, fue Procurador de la Misión en Carichana y posteriormente fue párroco de Cabruta y le tocó vivir de cerca las excentricidades del Comisario regio para la Expedición de Límites, don José de Iturriaga ${ }^{132}$. Según las papeletas de los dos bibliógrafos españoles, Uriarte y Lecina, escribió una Historia Natural del Orinoco ${ }^{133}$ de la que no tenemos otras noticias.

Tampoco podemos olvidar la colaboración del P. José Pagés al P. Hervás y Panduro con algunas "Noticias sobre el Nuevo Reino de Granada”134.

De igual manera debemos citar los aportes cartográficos del P. Joaquín Subías (1744-¿ ¿) quien fuera catedrático de retórica en la Universidad de Mantua y luego de Filosofía Moral en la de Turín ${ }^{135}$. En 1784 escribía el P. Felipe Salvador Gilij: "Y solamente sabe Dios cuánto trabajé por tener una [carta geográfica] muy exacta de Tierra Firme, llamada también Nuevo Reino de Granada. Pero aún lo la hay. Desde hace tiempos se espera una más pormenorizada y más cuidadosa de cuantas han aparecido, del Padre Joaquín Subías, versadísimo en esta materia”136.

Este acápite hay que completarlo con los mapas que produjo el P. Antonio Julián sobre la Provincia de Santa Marta y del Nuevo Reino ${ }^{137}$.

Pero sería el ámbito de la lingüística indígena donde la presencia de los misioneros de la Orinoquia cosecharían los mejores frutos. Y en este campo la figura señera que ha pasado a la posteridad en la literatura ilustrada gira en torno al misionero italiano Felipe Salvador Gilij.

Se podría afirmar que -en conjunto- ninguno de sus antecesores gozó de las singulares coyunturas que envolvieron su biografía para legar, no la síntesis, sino el mejor aporte jesuítico al estudio de los hombres que habitaron el gran río venezolano.

\footnotetext{
${ }^{129}$ Del Rey Fajardo, 1995: 539-540.

130 Gilij, 1955, T.IV: XX: "De los datos del corregimiento de Tunja soy deudor en gran parte al P. Enrique Rojas y a otro muy digno sujeto que por humildad quiere permanecer oculto”.

${ }^{131}$ Del Rey Fajardo, 1995: 568-569.

${ }^{132}$ ARAH, 9/3854. Carta del P. Antonio Salillas al P. Jaime de Torres. Cabruta y mayo 24 de 1763.

133 AIUL. Papeletas: Salillas, Antonio. “Mss.”.

${ }^{134}$ Lorenzo Hervás y Panduro. Idea dell’Universo, che contiene la Storia della vita dell'uomo, elementi cosmografici, viaggio estatico al mondo planetario, e Storia della terra. Cesena, Per Gregorio Blasini all’Insegna di Pallade, V, 157: "Fra le molte Persone pratiche delle cose delle Indie, che ho consultato per iscritto, ed a bocca, mi hanno favorito singolarmente colle loro notizie ... sul Regno di S. Fe ir Sr. Ab. D. Giuseppe Pajes".

135 AIUL. Papeletas: Subias, Joaquín.

${ }^{136}$ Gilij, 1955, T. IV: XXII.

137 Antonio Julián. Mapas de la Provincia de Santa Marta y del Nuevo Reino. Hervás y Panduro. Biblioteca., I, 309: "El abate Antonio Julián tiene cartas exactas de la provincia de Santa Marta y del Nuevo Reino de Granada, que piensa publicar en la historia de esa provincia y reino, que se imprimen en Madrid". Portillo, 1911: 332. Schlegelberger, 2001. 581-596.
} 
Además, entre la redacción del Saggio y sus experiencias misionales se interpone aproximadamente una década, espacio importante para la sedimentación de tantos hechos históricos que le tocó vivir.

Quizá el primer testimonio público en favor de Gilij proviene de Augusto Ludovico Schlözer, profesor de Historia y Política en la universidad de Göttingen, quien en carta del 21 de febrero de 1782 le escribía al ex-misionero. "Por tus escritos de las cosas del Orinoco, te felicito ..., principalmente por lo que dices en el tomo tercero sobre las lenguas americanas... Hace poco hemos recorrido las más septentrionales regiones de Europa y Asia, hemos investigado los idiomas de cada nación, hemos distinguido las lenguas matrices de los dialectos... Quedaba el mundo americano. Tu nos lo abres, varón eruditísimo, y nos enseñas las lenguas de pueblos antes apenas conocidos de nombre; y no solo nos las enseñas, sino que, lo que nadie hizo antes que tu, sobre ellas filosofas, y filosofas con sobriedad. Muchas gracias te darán por esta habilidad tuya muchos sabios, pero principalmente Buttner, mi íntimo amigo y colega, que en esta clase de estudio ha envejecido rodeado de pública alabanza. Y habrá quienes no sólo te quedarán agradecidos, sino que te corresponderán: habrá quienes comparen tus descubrimientos con los de nuestros autores, y reprueben que mucho que tu creías propio de tus americanos y de sus lenguas, se halla también particularmente en las de los finlandeses, eslavos, turcos..."

Pero, ciertamente, el basamento de la fama del P. Gilij radica en su tomo III de su Ensayo que lo ha convertido en el pionero de la etnolingüística colombo-venezolana ${ }^{139}$.

Es muy importante ubicar el contexto político-social en el que aparece el Ensayo de historia americana de Gilij pues, por una parte, se enmarca en una vertiente histórica definida: la revolución francesa, la norteamericana y la primera revolución industrial inglesa; y, por otro lado, se enrumba hacia los dominios de la nueva episteme, vale decir, en una nueva organización del saber que se construye en torno a tres grandes territorios: la vida, el lenguaje y el trabajo.

Nos encontramos en el momento en que se está evolucionando de la gramática general a la lingüística. Gilij ha vivido una etapa previa en la reducción orinoquense de La Encaramada en la que se desvivió por elaborar, como gramático, la gramática y el diccionario de las lenguas tamanaca y maipure; mas, desde su destierro romano emprende, en su Ensayo, un nuevo estudio del lenguaje pero en esta oportunidad desde la perspectiva histórica. Como afirma Jesús Olza el estudio histórico del lenguaje dentro de la Historia natural abre las puertas para el nacimiento de la Gramática histórica y comparada con los métodos de la Historia natural. La pérdida de la centralidad del verbo 'ser' propiciará la posibilidad de los estudios sociolingísticos y sicolingüísticos los cuales formarán parte del conjunto de disciplinas que tiene por objeto el estudio del lenguaje ${ }^{140}$.

\footnotetext{
${ }^{138}$ Gilij, 1955, T. III: 281.

${ }^{139}$ Mattei Muller, 1989: 91-104.

${ }^{140}$ Jesús Olza Zubiri (El Padre Felipe Salvador Gilij, lingüísta del Orinoco. Mss). Jesús Olza precisa el valor del autor del Saggio dentro de la evolución de la lingüística: "Gilij está en la fase en que la gramática deja de ser general y pasa a particular; Gilij además participa en el alumbramiento del comparatismo, pero hay un momento previo o simultáneo, muy importante en la historia de la lingüística, y es la inclusión del lenguaje dentro de la Historia Natural” (Olza, 1989: 441).
} 
Sus meditaciones romanas le llevaron a dilucidar con toda claridad los componentes de dos grandes familias lingüísticas: la caribe y la maipure. Habría que esperar un siglo para que Lucien Adam y Karl von den Stein confirmaran la vigencia de las conclusiones gilijianas y la validez de su tesis para las lenguas de la Orinoquia, la Amazonia, las Guayanas y el Caribe ${ }^{141}$.

En todo caso han venido apareciendo nuevos estudios en torno a la figura del P. Gilij que tratan de precisar su genuino aporte y de analizarlo desde puntos de vista muy distantes de la mera historia jesuítica ${ }^{142}$. En verdad, el destino de la Historia natural, afirma Duris, es la de aniquilarse progresivamente en cada una de las ciencias a las cuales ella sirve de anclaje $\mathrm{e}^{143}$.

Así pues, al misionero de La Encaramada hay que estudiarlo como uno de los pioneros en proponer el estudio del lenguaje dentro del ámbito de la Historia natural y se le puede considerar como el fundador del todavía incipiente del comparatismo de las lenguas del Orinoco y por extensión del Amazonas.

El ingreso a las grandes Bibliotecas de Escritores de la Compañía de Jesús lo tenía asegurado Gilij por su correspondencia ${ }^{144}$ y asesoría al P. Lorenzo Hervás y Panduro en la elaboración de su gran obra La Idea dell'Universo ${ }^{145}$. En efecto, en el tomo II de su Biblioteca Jesuítico Española ${ }^{146}$ el jesuita español le dedica una extensa reseña a su obra impresa y a la manuscrita.

También su inserción en los grandes repertorios bibliográficos europeos se consolidó, entre otras, por dos razones evidentes: la primera, por la fervorosa recepción que tuvo su Saggio en el mundo científico y literario de Italia y Francia ${ }^{147}$; la segunda, porque en 1785 -un año después de publicar su obra en italiano- se traducía al alemán $^{148}$ idioma en el que conocería varias traducciones. Para su evolución bibliográfica nos remitimos a la Bibliotheca Missionum de Streit ${ }^{149}$.

De modo mucho más lento fue penetrando el Ensayo de Historia Americana en la literatura histórica colombo-venezolana ${ }^{150}$, en la que de facto vino a formar parte del patrimonio cultural común después que la Academia Colombiana de Historia editara el tomo IV de su Ensayo en 1955 y la Academia Nacional de la Historia de Venezuela publicara la traducción castellana de los tres primeros volúmenes en 1965.

\footnotetext{
${ }^{141}$ Schmidt, 1962: 243-244, 250.

${ }^{142}$ Henley, 1989: 605-643. Arvejo-Jiménez y Biord-Castillo, 1989 : 69-90.

143 Duris, 1997 : 544.

${ }^{144}$ Del Rey Fajardo, 1971, T. II: 205-237.

145 Ibíd., T.I: 345-348.

${ }^{146}$ Hervás y Panduro, 2007, T. I: 753-756.

147 Véase: Nuovo Giornale di Letteratura de Modena, t. 33, pags., 233-251. También: Efemeride Lettararie di Roma, X: 1-3; 7-9; 9-12; 25-27; 33-35; 289-291; 297-299. XI: 153-155; 161-163; 169-171. XII: 97-99. L'Esprit des Journaux. París: 1781 (junio) 106-116; 1782 (enero) 75-90; 1784 (julio) 187209; 1785 (octubre) 160-169.

${ }^{148}$ Nachrichten vom Lande Guiana, dem Orinocoflus, und den dortigen Wilden. Aus dem Italienischen des Abbt Philip Salvator Gilii auszugsweise übersetzt. Hamburg, bei Carl Ernst Bohn, 1785, XVI-528p.

149 Streit, 1927, T.III: 302-303, 313, 314, 344.

${ }^{150}$ Pérez Hernández, 1989: 179-201.
} 
En la historia de la cultura colombo-venezolana debe considerársele como un genuino representante de la modernidad, a pesar de que su temática se haya reducido al autóctono orinoquense interpretado a través de la riqueza de su lengua, que es el vehículo de su cultura.

Pero también Gilij supo solicitar la colaboración de sus antiguos compañeros de la Orinoquia y a los que siempre les dedica un recuerdo.

El primer colaborador fue el P. José $\mathrm{M}^{\mathrm{a}}$. Forneri, compañero de fatigas en el río Orinoco y gran conocedor de la nación Yarura. Gilij recoge en su tomo IV parte de la correspondencia mantenida con su colega misionero ${ }^{151}$. Posteriormente le remitió a Roma la Gramática y diccionario de la lengua yarura ${ }^{152}$. También mantuvo su comercio epistolar con el P. Lorenzo Hervás y Panduro ${ }^{153}$.

El segundo fue el P. Manuel Padilla sucesor del P. José Gumilla en la Misión de San Ignacio de Betoyes. Colaboró con su entrega de Elementos gramaticales de la Lengua betoy ${ }^{154}$.

En el tomo II de Aportes jesuíticos a la filología colonial venezolana ${ }^{155}$ hemos recogido tanto el epistolario lingüístico mantenido por Gilij con Hervás y Panduro ${ }^{156}$, así como los aportes que suministraron al ilustre autor del Catálogo de las lenguas de las naciones conocidas los PP. Manuel Padilla ("Elementi Grammaticali della Lingua Betoy”) $^{157}$, José Forneri (“Elementi grammaticali della lingua Yarura”) ${ }^{158}$ y otros anónimos.

En el área de las traducciones el P. Juan Francisco Blasco publicó en Madrid en 1794 las Reflexiones sobre la Naturaleza de Sturm ${ }^{159}$.

Cierra la presencia neogranadina en tierras italianas el venezolano P. Alejandro Mas y Rubí (1749-1831) ${ }^{160}$, hijo de Maracaibo y quien tuvo que abandonar en 1767 la

151 AIUL. Papeletas: Forneri, José María: "Fragmentos de Cartas y noticias suyas. En las ps. 118-121, 123, 128-129, 136-137, 140-143, 171, 173-175, 216, del t. IV del Saggio di Storia Americana... del P. Felipe Salvador Gilij".

${ }^{152}$ AIUL. Papeletas: Forneri, José María: "Pensó en imprimirlo el P. Gilij como apéndice del t. IV de su obra y dejó de hacerlo creyendo que los iba a publicar el P. Hervás". Esta gramática es distinta a la que dejó en el Orinoco al tiempo de la expulsión de 1767. La segunda fue redactada en Italia, muchos años después, con las imperfecciones que ello supone.

${ }^{153}$ Véase: AIUL. Papeletas: Forneri, José María: "1. Carta del Sr. Forneri al P. Hervás sobre su misión de la nación yarura y sobre los idiomas de las naciones a esta inmediatas. Tráela el mismo Hervás en su Catálogo de las Lenguas..., I, 225-227". En realidad, la esencia del contenido se refiere fundamentalmente a los yaruros.

${ }^{154}$ El texto original italiano reposa en: ARSI. Opera Nostrorum, 342, fols., 193-201v. Publicamos la traducción española en: Aportes jesuíticos a la filología colonial venezolana. Caracas, II (1971) 261-276.

155 Del Rey Fajardo, 1971, T.II: 205-316.

156 Ibíd., 1971, T.II: 207-237 publicamos la correspondencia Gilj-Hervás y Panduro que reposa en el Archivo Vaticano: Vat. Lat., 9802.

157 ARSI. Opera Nostrorum, 342, fols., 193r-201v. [cambia Manuel por José]

${ }^{158}$ Ibíd., fols., 202r-209v.

${ }^{159}$ Reflexiones sobre la Naturaleza, o consideraciones de las obras de dios en el orden natural. Escritas en alemán para todos los días del año. Por M. C. C. Sturm. Traducidas al Francés y de éste al Castellano con Notas instructivas y curiosas. Madrid, año de 1794. 4 tomos en 8 . Véase: Hervás y Panduro, 2007, T. I: 577-578. Uriarte, 1904, T. II: 88. Del Rey Fajardo, 1995: 96-97. 
Universidad Javeriana donde iniciaba su formación. Desterrado a Italia en 1767 concluyó su carrera eclesiástica en la ciudad de Gubbio en donde recibió la ordenación sacerdotal $^{161}$. El 1 de enero de 1774 vivía en Gubbio ${ }^{162}$. Después debió residenciarse en Roma y allí vivía en $1793^{163}$. Consagrado al estudio de Geografía y de la Astronomía debió dedicarse también a la docencia ${ }^{164}$. Restablecida la Compañía de Jesús ingresó de nuevo a ella el 25 de marzo de $1816^{165}$. Sus últimos años transcurren en el ejercicio de las virtudes sacerdotales. Murió en la ciudad eterna el 12 de octubre de $1831^{166}$.

Hervás nos ha conservado su producción científica hasta antes de concluir el siglo XVIII pero de su larga vida del XIX habrá que seguir investigando la prolífica acción de este jesuita marabino.

Escribió: Elementos científicos de geometría con aplicación de sus proposiciones a las demás artes y ciencias ${ }^{167}$; Geografía astronómica, física y política ${ }^{168}$; Astronomía física $^{169}$; Cronología con las Tablas del jesuita Musuner, añadidas y reducidas a mejor método; se añade la chronología de los soberanos de León, Navarra, Aragón, Borgoña, Austria y Orleans ${ }^{170}$; Tabla cronologica o prospecto de la cronología ${ }^{171}$; Compendio de la historia profana desde la creación del mundo hasta el año 1764 de la era cristiana ${ }^{172}$ e Historia del imperio romano, de Alemania, Francia, España, Portugal, Inglaterra y del Imperio Otomano con relación de la vida de Mahoma $^{173}$.

También debemos mencionar muchas colaboraciones perdidas o desconocidas de los abolidos neogranadinos. Una fuente interesante nos la ofrece Lorenzo Hervás y Panduro en su obra Idea dell'Universo ${ }^{174}$ en donde descubrimos los siguientes colaboradores. En el tomo I aparecen Tadeo Vergara y Leandro Gonsalves ${ }^{175}$. En el

\footnotetext{
${ }^{160}$ Ibíd.: 370-371.

${ }^{161}$ Hervás y Panduro, 2007, T.I: 631.

${ }^{162}$ Archivo de Monumenta Historica Societatis Jesu. Armadio 10. Relacion individual de los Ex-jesuitas muertos de las Once Provincias de España e Indias desde la expulsión hasta el día 30 de junio de 1777. Por Don Juan Antonio de Archimbaud. Provincia del Nuevo Reino de Granada. No ${ }^{\circ}$ 4371. AHN. Jesuitas. Serie Temporalidades. Legación Urbino, n. 28, 33, 81. (Se trata de recibos de pensiones de 1775 y 1776).

163 Hervás y Panduro, 2007, T.I: 631.

${ }^{164}$ Summarium vitarum Provinciae Romanae. I, 14: "Doctus in Geographia et Astronomia, quas dum in saeculo viveret, plures ingeniosos alumnos privatim docuit".

165 ARSI. Catálogo, 1820; 1826; 1829; 1830; 1831.

${ }^{166}$ ARSI. Catálogo, 1832.

${ }^{167}$ Hervás y Panduro, 2007, T.I: 631. "Un tomo con 200 figuras que envió a la Secretaría de Indias en Madrid para la impresión".

${ }^{168}$ Ibíd.: "Dos tomos en lengua española".

${ }^{169}$ Ibíd.: "Un tomo en lengua española".

${ }^{170}$ Ibídem.

${ }^{171}$ Ibíd.: "En lengua latina".

172 Ibíd.: "Dos tomos en lengua italiana".

173 Ibíd.: "Seis tomos en lengua italiana".

${ }^{174}$ Hervás y Panduro, 1778-1792.

175 Ibíd. Tomo I. Concezione, Nascimento, infanzia e puerizia dell’Uomo. In Cesena, per Gregorio Biasini, 1778.
} 
tomo V: Esteban Lloret ${ }^{176}$. En el tomo IX: Francisco Asso, Miguel Hoyos y Salvador Pérez ${ }^{177}$.

\section{Consideraciones finales}

Pero cuando se analiza fríamente la biografía del retorno de la Compañía de Jesús restaurada a tierras americanas surge de nuevo la pregunta: ¿Hubo realmente una quiebra del imaginario jesuítico en la conciencia histórica de los pueblos americanos?

La cronología del retorno habla por sí sola pues el regreso de los jesuitas al continente descubierto por Colón se regiría por el siguiente cronograma: México en $1816^{178}$; Argentina en $1836^{179}$; Uruguay en $1841^{180}$; Colombia ${ }^{181}$ y Chile ${ }^{182}$ en 1842 ; Ecuador $^{183}$ y Guatemala ${ }^{184}$ en 1851; Cuba en $1852^{185}$; Puerto Rico en $1858^{186}$; El Salvador en $1869^{187}$; Perú en $1871^{188}$; Panamá en $1872^{189}$; Venezuela en $1916^{190}$; Paraguay en $1926^{191}$ y República Dominicana a partir de $1932{ }^{192}$.

Pero más allá de la memoria histórica surgía una terrible realidad. De los 228 jesuitas que en 1767 laboraban en el Nuevo Reino de Granada, Venezuela y República Dominicana solamente 14 sobrevivieron a la catástrofe que tuvo su final el 7 de agosto de 1814: 4 neogranadinos, 1 venezolano y 9 españoles.

Si en la época colonial habían logrado tener una presencia importante en todo el continente de forma tal que en 1767 fueron desterrados 2.746 ignacianos, en 1914 la Compañía de Jesús mantenía en Latinoamérica 1.630 seguidores. Estamos sin duda en la prueba fehaciente de la profunda herida que habían legado Carlos III y el todopoderoso Pombal a la Iglesia latinoamericana ${ }^{193}$.

Triste balance de una guerra ideológico-política en la que los vencidos pudieron al fin ver reivindicados sus derechos pero tan solo pudieron convertirse en testigos para

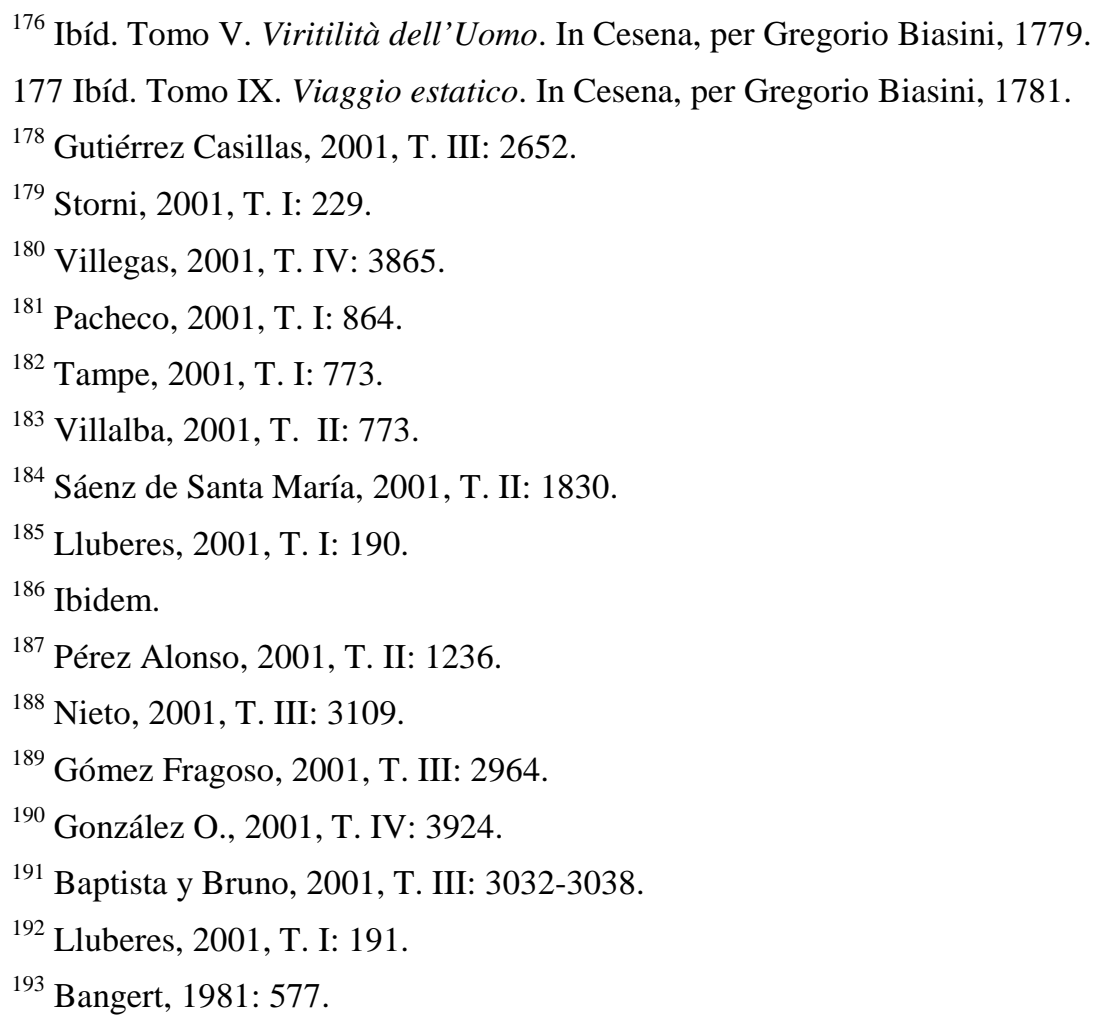


dar fe de su triunfo pero sin poder dejar un ejército de seguidores que capitalizaran su victoria. Fue el precio de una guerra en la que todos perdieron. Y los vencidos llegados a vencedores no pudieron celebrar su victoria pues la mayoría había sido víctima del gran naufragio y sólo pudieron presenciarla desde las tumbas desconocidas en que yacen en tierras de Italia.

Y por ello cerramos el artículo con la dedicatoria que les dedica el historiador chileno Walter Hanisch pues es el justo reconocimiento a todos los que se quedaron en el camino: "Son como restos de un inmenso naufragio en que quedan flotando a la deriva los tesoros y los humildes enseres hasta que los traga el mar. Sin patria y sin idioma, sin cariño y sin su Compañía, ancianos, pobres y enfermos, ellos y sus escritos fueron errantes hacia el olvido y sólo en el regazo de la muerte se abrieron sus ojos a una más luminosa esperanza"194.

\section{Referencias}

\section{Archivos}

AIUL, Archivo inédito Uriarte-Lecina, Universidad de Comillas, Madrid.

ARSI, Archivo Romano de la Compañía de Jesús.

ARAH, Archivo de la Real Academia de Historia, Madrid.

ANB, Archivo Nacional de Colombia.

AHN, Archivo Histórico Nacional de Madrid.

ANCh, Archivo Nacional de Chile.

APT, Archivo de la Provincia de Toledo, Alcalá de Henares.

\section{Bibliografía}

Acuña, Cristóbal de (1641). Nuevo descubrimiento del gran río de las Amazonas el año de 1639. Madrid: Imprenta del Reyno.

Aguirre Elorriaga, Manuel (1941). La Compañía de Jesús en Venezuela. Caracas: Editorial Cóndor.

Álvarez Arteta, Segundo (1901). La cuestión de límites entre las repúblicas del Ecuador y el Perú, apuntes y documentos. Sevilla: Escuela tipográfica y librería salesianas.

Arévalo-Jiménez, Nelly y Biord-Castillo, Horacio (1989). "Reflexiones antropológicas sobre el Ensayo de Historia Americana de Felipe Salvador Gilij". Montalbán. Caracas, 21.

Balzátegui, Manuel (1925). Noticia de la vida, virtudes y trabajos del apostólico varón Padre Roque Lubian que, después de 40 y más años de misionero del Orinoco y Meta, murió en destierro de Italia y Gubbio 8 de mayo de 1781. En: Uriarte, José Eug. de y Lencina, Mariano. Biblioteca de escritores de la Compañía de

\footnotetext{
${ }^{194}$ Hanisch, 1972: 170.
} 
Jesús pertenecientes a la antigua Asistencia de España, desde sus orígenes hasta el año de 1773. Madrid: Viuda de López del Horno, I.

Bangert, William V. (1981). Historia de la Compañía de Jesús. Santander: Editorial Sal Terrae.

Baptista, Javier (2001). “América hispana. VII. Lingüística”. En: O’Neill y Domínguez, cit. T. I.

Baptista, Javier (2001). “Sánchez Labrador, José”. En: O’Neill y Domínguez, cit. T. IV.

Baptista, Javier y Bruno Cayetano (2001). “Paraguay”. En: O’Neill y Domínguez, cit. T. III.

Batllori, Miguel (1951). "El archivo lingüístico de Hervás en Roma y su reflejo en Wilhelm von Humboldt". Archivum Historicum Societatis Iesu. Roma, 20.

Batllori, Miguel (1953). El abate Viscardo. Historia y mito de la intervención de los jesuitas en la Independencia de América. Caracas: Instituto Panamericano de Geografía e Historia.

Batllori, Miguel (1979). Del descubrimiento a la independencia. Estudios sobre Hispanoamérica y Filipinas. Caracas: Universidad Católica Andrés Bello.

Batllori, Miguel (2001). “Andrés y Morell, Juan”. En: O’Neill, Charles E. y Domínguez, Joaquín $\mathrm{M}^{\mathrm{a}}$, Diccionario histórico de la Compañía de Jesús, I, Universidad Pontifica de Comillas.

Borrás i Feliu, Antoni (1995). "El Col-legi de Sta. Maria i St. Jaume, dit de Cordelles i la Companyia de Jesús". Analecta Sacra Tarraconensia, 37.

Brading, David (1991). Orbe indiano. De la monarquía católica a la república criolla, 1492-1867. México: Fondo de Cultura Económica.

Burrus, Ernest J. (2001). “Kino (Chini, Chino) Eusebio Francisco”. En: O’Neill Domínguez cit. T. III.

Campeau, Lucien (2001). “Marquette, Jacques”. En: O’Neill - Domínguez cit. T. III.

Cartas familiares (1786) del Abate D. Juan Andrés a su hermano D. Carlos Andrés, dándole noticia del viage que hizo a varias ciudades de Italia en el año 1785. publicadas por el mismo D. Carlos, Madrid: Antonio de Sancha.

Clavigero, Francisco Javier (1780-1781). Storia Antica del Messico cavata da'mighori storici spagnuoli e da' manoscritti... divisa in dieci libri, e corredata di carte geografiche e di varie figure e dissertazioni sulla Terra, sugli animali, e sugli abitatori del Messico. Cesena, per Gregorio Biasini all' Insegna di Pallade.

Coleti, Giandomenico (1771). Dizionario Storico-Geografico Dell'america Meridionale. In Venezia: Nella Stamperia Coleti.

Cunill Grau, Pedro (1989). "Felipe Salvador Gilij, geógrafo dieciochesco de la cuenca del Orinoco y del Amazonas venezolano". Montalbán. Caracas, 21.

Chantre y Herrera, José (1901). Historia de las Misiones de la Compañía de Jesús en el Marañón Español (1637-1767). Madrid: Imprenta de A. Avrial. 
Dávila y Arrillaga, José Mariano (1889). Continuación de la Historia de la Compañia de Jesus en Nueva España del P. Francisco Javier Alegre. Puebla: Imp. del Colegio Pio de artes y oficios, II.

Del Rey Fajardo, José (1971). Aportes jesuíticos a la filología colonial venezolana. Caracas, Ministerio de Educación, II.

Del Rey Fajardo, José (1995). Bio-bibliografía de los Jesuitas en la Venezuela colonial. San Cristóbal-Santafé de Bogotá: Universidad Católica del Táchira-Pontificia Universidad Javeriana.

Del Rey Fajardo, José (2002). Catedráticos jesuitas de la Javeriana colonial. Bogotá: CEJA.

Del Rey Fajardo, José (2006). Biblioteca de escritores jesuitas neogranadinos. Bogotá: Editorial Pontificia Universidad Javeriana.

Diderot, Denis y D' Alembert, Jean-le-Rond (1751). Encyclópedie, ou Dictionnaire raisonné des sciences, des arts et des métiers par une societé de gens de lettres, mis en ordre \& publié par M. Diderot... \& quant à la Partie Mathématique, par M. D'Alembert...; tome premier. A Paris: chez Briasson... chez David l'aîné... chez Le Breton... imprimeur ordinaire du Roy... chez Durand.

Dobrizhoffer, Martín (1784). Historia de Abiponibus Esquestri, Bellicosaque Paraquariae Natione locupletata... Viennae: Typis Josephi Nob. De Kurzbek.

Duquesne, Ignacio. Relazione sopra il viaggio dei Gesuiti Della Provincia di Sta. Fede di Bogotá. (APT. Leg., 700).

Duris, Pascal (1997). "Histoire naturelle”. En: Delton, Michel (Ed.). Dictionnaire européen des Lumières. Paris : Presses Universitaires de France.

Echard, Laurence (1779). Dictionnaire geographique-portatif... traduit de l'anglois sur la treizieme édition de Laurent Echard, avec des additions \& des corrections considérables par monsieur Vosgien, chanoine de Vaucouleurs. A Paris: chez Les Libraires Associes.

Esteve Barba, Francisco (1965). Cultura virreinal. Barcelona-Madrid: Salvat Editores.

Fernández G., Enrique (2001). “Acuña, Cristóbal de”. En: O’Neill y Domínguez, cit, T. I.

Fontanals, Reis (1994). La Fundació canònica i imperial del Collegi de Cordelles. Barcelona: Biblioteca de Catalunya

Fritz, Samuel (1707). El gran río Marañón o Amazonas con la misión de la Compañía de Jesús. Quito, [s.n.].

Furlong Cardiff, Guillermo (1936). Cartografía jesuítica del Río de la Plata. Buenos Aires: Talleres S. A. Casa Jacobo Peuser.

Furlong, Guillermo (1969). Historia social y cultural del Río de la Plata 1536-1810. El trasplante cultural: Ciencia. Buenos Aires: Tip. Editora Argentina.

Galán García, Agustín (1995). El Oficio de Indias de los jesuitas de Sevilla 1566-1767. Sevilla: Fundación Fondo de Cultura de Sevilla. 
Ganuza, Marcelino (1921). Monografía de las Misiones vivas de Agustinos Recoletos (Candelarios) en Colombia. Siglo XVII-XX. Bogotá: Imprenta de San Bernardo, II.

Gerbi, Antonello (1960). La disputa del Nuevo Mundo. México: Fondo de Cultura Económica.

Gerbi, Antonello (1982). La disputa del Nuevo Mundo. Historia de una polémica 17501900. México: Fondo de Cultura Económica

Gilij, Felipe Salvador (1955). Ensayo de Historia Americana. Bogotá: Academia Colombiana de Historia, IV.

Gilij, Felipe Salvador (1965). Ensayo de historia americana. Caracas, Academia Nacional de la Historia, I.

Goic, Cedomil (ed.) (1988). Historia y crítica de la literatura hispanoamericana. Barcelona: Crítica, I.

Gómez Fragoso, Jesús (2001). “Panamá”. En: O’Neill y Domínguez, cit. T. III.

Gómez, Jesús (2001). O’Neill y Domínguez cit. T. IV.

González Cruz, Francisco (2001). Globalización y Lugarización. La Quebrada: Universidad Valle del Momboy y Centro de Estudios Provinciales y Locales.

González O., Herman (2001). “Venezuela”. En: O’Neill y Domínguez, cit. T. IV.

González Stephan, Beatriz (1993). "Sujeto criollo/conciencia histórica: la historiografía literaria en el período colonial”. En: Anadón, José (ed.). Ruptura de la conciencia hispanoamericana: época colonial. México, D.F.: Fondo de Cultura Económica.

Gutiérrez Casillas, José (2001). “México”. En: O’Neill y Domínguez, cit. T. III.

Hanisch, Walter (1972). Itinerario y pensamiento de los jesuitas expulsos de Chile (1767-1815). Santiago de Chile: Editorial Andrés Bello.

Hanisch, Walter (1976). Juan Ignacio Molina. Sabio de su tiempo. Santiago de Chile: Ediciones Nihil Mihi.

Henley, Paul (1989). "Los Tamanaku". Paramillo. San Cristóbal, 8.

Hervás y Panduro, Lorenzo (1778-1792). Idea dell'Universo que contiene la Storia della vita dell'uomo, elementi cosmografici, viaggio estatico al mondo planetario, e Storia Della terra. In Cesena: per Gregorio Biasini, 22 vols.

Hervas y Panduro, Lorenzo (2007). Biblioteca jesuítico-española (1759-1799). Estudio introductorio, edición crítica y notas: Antonio Astorgano Abajo. Madrid: Libris: Asociación Libreros de viejo.

Humboldt, Alejandro de (1956). Viaje a las regiones equinocciales del Nuevo Continente. Caracas: Ministerio de Educación.

Jolis, José (1789). Saggio sulla storia naturale della provincia del Gran Chaco, e sulle pratiche e su' costumi dei popoli che l'abitano insieme con tre giornali... In Faenza: per Lodovico Genestri. 
Julián, Antonio (1787). La Perla de América, Provincia de Santa Marta, reconocida, observada y expuesta en discursos históricos por Don Antonio Julián. Madrid: don Antonio de Sancha.

Julián, Antonio (MDCCXC). Trasformazione Dell America ossia Trionfo Della S. Chiesa Sulla Rovina della Monarchia del Demonio in America Dopo La Conquista Fattane Da' Monarchi Della Spagna: Con Riflessioni Apologetiche, e coll' aggiunta di una Dissertazione Critico-Espositiva, nella quale spiegandosi le parole di S. Pietro Epi I. c. 3. Qui increduli fuerant in diebus Noe, cum fabricaretur Arca vv. 18, 19, 20. Dimostrasi con valide ragioni, essere tutto ció accaduto nell'America. Opera Del Sacerdote Antonio Julián per molti anni Missionario in quelle parti. In Roma.

Julián, Antonio [1787] (1951). La perla de América provincia de Santa Marta. Bogotá: Biblioteca Popular de Cultura Colombiana.

Julián, Antonio (1994). Monarquía del Diablo en la gentilidad del Nuevo Mundo Americano. Transcripción e introducción por Mario Germán Romero. Santafé de Bogotá: Instituto Caro y Cuervo.

Kino, Eusebio (1913-1922). Las misiones de Sonora y Arizona. México: Publicaciones del Archivo General de la Nación y Editorial Cultura.

Landivar, Rafael (1781). Rusticatio Mexicana, seu rariora quaedam ex agris mexicanis decerpta, atque in libros decem distributa. Mutinae [Módena]: apud Societatem Typographicam.

Leite, Serafím (1938-1950). História da Companhia de Jesús no Brasil. Lisboa-Río de Janeiro: Civilizaçao Brasileira. 10 vols. Reedición facsimilar Sao Paulo, Edición patrocinada por Petrobras. "Escritores. Tomo Primero” (2004).

Lozano, Pedro (1733). Descripción Chorographica del terreno, Rios, Arboles y Animales de las dilatadíssimas Provincias del Gran Chaco, Gualamba y de los ritos y costumbres de las innumerables naciones barbaras e infieles que la habitan... Córdoba: En el Colegio de la Assumpcion, por Joseph Santos Balbàs.

Luengo, Manuel. Diario, sobre el destierro y vicisitudes de la Provincia de Castilla la Viexa, después más en general de toda la Compañía, aunque siempre con mayor particularidad de la dicha Provincia de Castilla. (Mss.). Manuscrito que reposa en el Archivo de Loyola (Guipúzcoa); consta de 63 tomos (falta el tomo IV correspondiente al año 1770). Han sido publicados algunos tomos por la investigadora de la Universidad de Alicante, Inmaculada Fernández Arrillaga. A partir del 2001. La cita es: Manuel LUENGO. Diario, 7 de junio de 1776.

Lynch, John (1989). Las revoluciones hispanoamericanas, 1808-1826. Barcelona: Ariel.

Lluberes, Antonio (2001). “Antillas”. En: O’Neill y Domínguez, cit. T. I.

Maroni, Pablo (1889). Noticias auténticas del famoso río Marañón, y misión apostólica de la Compañía de Jesús de la Provincia de Quito. Madrid: establecimiento tipográfico de Fortanet.

Marquette, Jacques (1855). Récit des voyages et des découvertes du R. Père Jacques Marquette de la Compagnie de Jesús en l'année 1673 et aux suivantes...et le 
journal autographe du P. Marquetteen 1674 et 1675, avec la carte de son voyage tracée de sa main. Albany: Imprimerie de Weed, Parsons et C.

Mateos, Francisco (1944). “Antecedentes de la entrada de los jesuitas españoles en las Misiones de América”. Missionalia Hispanica. Madrid.

Mattei Muller, Marie-Claude (1989). "Gilij, pionero de la etnolingüística venezolana: sus métodos y logros". Montalbán. Caracas, 21.

Molina, Juan Ignacio (1782). Saggio sulla storia Naturale del Chili. Bologna: Stamperia di S. Tomaso.

Murr, Christoph Gottlieb von (1785). Reisen einiger Missionarien der Gesellschaft Jesu in Amerika. Aus ihren eigenen Aufsätzen herausgegeben von Christoph Gottlieb von Murr. Mit einer Landkarte und Kupfern. Nürnberg, bei Johann Eberhard Zeh

Nava Rodríguez, Teresa (1989). Reformismo ilustrado y americanismo: la Real Academia de la Historia, 1753-1792. Madrid: Universidad Complutense.

Navia Méndez-Bonito, Silvia (2005). "Las historias naturales de Francisco Javier Clavigero, Juan Ignacio de Molina y Juan de Velasco”. En: Millones Figueroa, Luis y Ledesma, Domingo (Eds.). El saber de los jesuitas, historias naturales y el Nuevo Mundo. Frankfurt-Madrid, Vervuert e Iberoamericana.

Nieto, Armando (2001). “Perú”. En: O’Neill y Domínguez, cit. T. III.

Olza, Jesús (1989). "El Padre Felipe Salvador Gilij en la historia de la lingüística venezolana". Paramillo. San Cristóbal, 8.

Ortega, José (1754). Apostólicos afanes de la Compañía de Jesús, escritos por un Padre de la misma sagrada Religión de su provincia de México. Barcelona: Pablo Nadal.

Osorio Tejada, Nelson (1993). "Formación del pensamiento crítico literario en la colonia”. En: Anadón, José (ed.). Ruptura de la conciencia hispanoamericana. Madrid-México, D.F.: Fondo de Cultura Económica de España.

Pacheco, Juan Manuel (2001). “Colombia”. En: O’Neill y Domínguez, cit. T. I.

Pagden, Anthony (1990). Spanish Imperialism and the Political Imagination. Studies in European and Spanish-American Social and Political Theory. New Haven, Yale University Press.

Pauw, Cornelius de (1771). Recherches philosophiques sur les Americains ou mémoires intéressants pour servir à l'histoire de l'espece humaine. Par M. de P***. Avec une dissertation sur l'Amérique \& les Américains, par Dom Pernety. ... London, [s. n.].

Peralta Ruiz, Víctor (2006). Patrones, clientes y amigos. El poder burocrático indiano en la España del siglo XVIII. Madrid: Consejo Superior de Investigaciones Científicas.

Pérez Alonso, Manuel Ignacio (2001). “El Salvador”. En: O’Neill y Domínguez, cit. T. II. 
Pérez Hernández, Francisco Javier (1989). "Testimonios venezolanos sobre la obra lingüística de Felipe Salvador Gilij". Montalbán. Caracas, $\mathrm{n}^{\circ} .21$.

Portillo, E (1911). "Lorenzo Hervás. Su vida y sus escritos (1735-1809)". Razón y Fe. Madrid, 31.

Quecedo, Francisco (1952). "Manuscritos teológico-filosóficos coloniales santafereños". Ecclesiastica Xaveriana. Bogotá, 2.

Reynal, François (1770). Histoire philosophique et politique des établisssements et du comerce des Européens dans les deux Indes. Amsterdam, [s. n.].

Robertson, William (1777). History of America. London: Printed for W. Strahan; T. Cadell, in the Strand, and J. Balfour, at Edinburgh.

Robinson, David (1969). “El significado de 'lugar' en América Latina”. Revista de la Universidad Nacional de Colombia. Medellín, 26.

Rodrigues de Mello, Josephi, Lusitani Portuensis (1781) De Rusticis Brasiliae Rebus Carminum Libri IV. Roma: ex Typographia Fratrum Pucinelliorum prope Templum S. Mariae in Valicella.

Rodríguez, Manuel (1684). El Marañón y Amazonas. Madrid: impr. de A. Gonçalez de Reyes

Romero, Mario Germán (1994). "El Padre Antonio Julián y su libro Monarquía del Diablo". En: Julián, Antonio (1994). Monarquía del Diablo en la gentilidad del Nuevo Mundo Americano. Santafé de Bogotá: Instituto Caro y Cuervo.

Ronan, Charles E. y Gómez F. Jesús (2001). “Clavigero (Clavijero), Francisco Javier Mariano”. En: O’Neill y Domínguez, cit. T. I.

Sáenz de Santa María, Carmelo (2001). “Guatemala”. En: O’Neill y Domínguez, cit. T. II.

Sáinz Ollero, Héctor, et alii (1989). José Sánchez Labrador y los naturalistas jesuitas del Río de la Plata: la aportación de los misioneros jesuitas del siglo XVIII a los estudios medioambientales en el Virreinato del Río de la Plata, a través de la obra de José Sánchez Labrador. Madrid: Secretaría General Técnica, Centro de Publicaciones, Ministerio de Obras Públicas y Urbanismo.

Santos Hernández, Ángel (1992). “Actividad misionera de los jesuitas en el continente americano”. En: Del Rey Fajardo, José (Ed.). Misiones jesuíticas en la Orinoquia. San Cristóbal: Universidad Católica del Táchira, I.

Schlegelberger, Bruno (2001). “Antonio Julián y su descripción de las culturas autóctonas”. En: Tietz, Manfred (Ed.). Los jesuitas españoles expulsos. Su imagen y su contribución al saber sobre el mundo hispánico en la Europa del siglo XVIII. Madrid-Frankfurt/M, Iberoamericana-Vervuert.

Schmidt, Wilhelm (1962). Die Sprachfamilien und Sprachkreisen der Erde. Heidelberg.

Sommervogel (1896). Bibliothèque de la Compagnie de Jésus. Bruxelles, SchepensParís, Picard, VII.

Storni, Hugo (2001). “Argentina”. En: O’Neill y Domínguez, cit. T. I.

Streit, Rob. (1927). Bibliotheca Missionum. Freiburg/Br, Herder \& Co., III. 
Tampe, Eduardo (2001). “Chile”. En: O’Neill y Domínguez, cit. T. I.

Torres, Jaime de (seudónimo de Pedro Lozano) (1763). Breve relación de la Vida, y virtudes del venerable jesuita y apostólico P. Juan Saloni... Madrid: por Joaquín Ibarra [segunda edicion en Barcelona, 1893].

Uriarte, J. Eug. (1904). Catálogo razonado de obras anónimas y seudónimas de autores de la Compañía de Jesús pertenecientes a la antigua asistencia española. Madrid: Establecimiento Tipográfico <Sucesores de Rivadenyra> Impresores de la Real Casa, II

Uricoechea, Ezequiel (1872). "Los americanistas". El Americano. París, nº 12 (junio 11 de 1872)

Valmont-Bomare, Jacques Christophe (1764). Dictionnaire raisonné universel d'histoire naturelle: contenant l'histoire des animaux, des végétaux et des minéraux... \& des autres principaux phénomenes de la nature avec l'histoire et le description des drogues simples tirées des trois regnes... par M. Valmont de Bomare... A Paris: chez Didot, le jeune... [et. al.].

Vargas Ugarte, Rubén (1964). La Carta a los españoles americanos de don Juan Pablo Viscardo y Guzmán. Lima: Librería e Imprenta Gil. 2a ed.

Velasco, Juan de (1981). Historia del Reino de Quito en la América Meridional. Edición, prólogo, notas y cronología [por] Alfredo Pareja Diezcanseco. Caracas: Biblioteca Ayacucho

Venegas, Miguel (1757). Noticia de la California y de su conquista temporal y espiritual hasta el tiempo presente. Madrid: en la Imprenta de la Viuda de Manuel Fernández.

Villalba, Jorge (2001). “Chantre y Herrera, José”. En: O’Neill y Domínguez, cit, T. I.

Villalba, Jorge (2001). “Ecuador”. En: O’Neill y Domínguez, cit. T. II.

Villalba, Jorge (2001). “Maroni, Pablo”. En: O’Neill y Domínguez, cit, T. III.

Villalba, Jorge (2001). “Rodríguez Villaseñor, Manuel”. En: O’Neill y Domínguez, cit, T. IV.

Villalba, Jorge (2001). “Velasco Petroche, Juan de”. En O’Neill y Domínguez, cit. T. IV

Villalba, Jorge y Domínguez, J. Ma (2001). “Fritz, Samuel”. En: O’Neill y Domínguez, cit, T. II.

Villegas, Juan (2001). “Uruguay”. En: O’Neill y Domínguez, cit. T. IV. 